Cipango Cahiers d'études japonaises

$20 \mid 2013$

Nouveaux regards sur les arts de la scène japonais I

\title{
Le gagaku, musique de l'Empire : Tanabe Hisao et le patrimoine musical comme identité nationale
}

Gagaku, Music of the Empire: Tanabe Hisao and Musical Heritage as National Identity

\section{Seiko Suzuki}

\section{(2) OpenEdition \\ Journals}

\section{Édition électronique}

URL : https://journals.openedition.org/cipango/1999

DOI : 10.4000/cipango.1999

ISSN : 2260-7706

Éditeur

INALCO

Édition imprimée

Date de publication : 30 octobre 2013

ISSN : 1164-5857

\section{Référence électronique}

Seiko Suzuki, «Le gagaku, musique de l'Empire : Tanabe Hisao et le patrimoine musical comme

identité nationale », Cipango [En ligne], 20 | 2013, mis en ligne le 18 avril 2015, consulté le 30 juin 2021. URL : http://journals.openedition.org/cipango/1999; DOI : https://doi.org/10.4000/cipango.1999

Ce document a été généré automatiquement le 30 juin 2021.

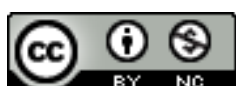

Cipango est mis à disposition selon les termes de la Licence Creative Commons Attribution - Pas d'Utilisation Commerciale 4.0 International. 


\title{
Le gagaku, musique de l'Empire : Tanabe Hisao et le patrimoine musical comme identité nationale
}

\author{
Gagaku, Music of the Empire: Tanabe Hisao and Musical Heritage as National \\ Identity
}

Seiko Suzuki

1 Au début $\mathrm{du} x \mathrm{xx}^{\mathrm{e}}$ siècle, Tanabe Hisao 田邊尚雄 (1883-1984), physicien acousticien, musicologue, premier ethnomusicologue japonais et premier président de la Société orientale de musique (Tōyō ongaku gakkai 東洋音楽学会) de Tōkyō, élabore une histoire de la musique japonaise et asiatique qui fera date. Celle-ci présente le gagaku comme une musique originale, appartenant certes au patrimoine japonais, mais également représentative d'une culture partagée par tous les pays asiatiques. Les théories de Tanabe ont largement contribué à ce que le gagaku soit désigné, le 12 mai 1955, comme l'un des «biens culturels immatériels importants » (jūyō mukei bunkazai 重要無形文化財) du Japon par le ministère de l'Éducation ${ }^{1}$. À la suite de ses travaux, le gagaku est en effet apparu comme étant la musique la plus ancienne du Japon, restée immuable au cours des siècles, preuve de la pérennité et de l'immutabilité de l'identité culturelle du peuple japonais ${ }^{2}$. Si aujourd'hui, il existe divers groupes de gagaku privés, selon le Comité pour la protection des biens culturels du ministère de l'Éducation seul le département de Gagaku de l'Agence impériale "conserve pour les générations futures le gagaku authentique et peut l'exécuter de façon artistique » ${ }^{3}$. En d'autres termes, l'invariabilité et la continuité de l'institution des musiciens de cour permettent l'authenticité du gagaku. Mais cette musique est posée également comme la plus « universelle », car dépositaire d'un patrimoine dépassant largement les frontières de l'État japonais. Ici, il ne faut pas oublier que la définition du gagaku de Tanabe prend place dans un contexte d'impérialisme et de colonialisme japonais menant, au tournant des années 1940, au concept de "musique de la Grande Asie orientale " (Daitōa ongaku 大東亜音楽), alors que le Japon essaie de s'instituer au centre d'un grand ensemble asiatique. 
2 Ce sont précisément ces postulats de l'immutabilité, de l'identité, de l'universalité et, in fine, la conception même de «bien culturel » ou de «patrimoine » que nous voudrions interroger dans le présent article. Pour ce faire, nous étudierons la définition du gagaku comme répertoire spécifique dans une perspective historique, et analyserons le processus suivant lequel cette musique a accédé au rang de «bien culturel immatériel important » du Japon. Nous nous attacherons surtout au rôle tenu par Tanabe Hisao dans la construction de cette représentation.

\section{Le gagaku prémoderne}

3 L'étiquette de gagaku actuelle s'applique donc strictement à l'ensemble du répertoire exécuté par les vingt-cinq musiciens du département de Gagaku du bureau des Cérémonies de l'Agence impériale (Kunaichō shikibushoku gakubu 宮内庁式部職楽部). De façon générale, on répartit ce répertoire en trois catégories :

1. Kokufū kabu 国風歌舞 (pièces vocales et à danser proprement japonaises).

2. Gairai gakubu 外来楽舞 (pièces instrumentales et à danser importées).

3. Utaimono 歌物 (pièces vocales) ${ }^{4}$.

4 On peut distinguer deux grands types d'occasions d'exécution du gagaku: les cérémonies rituelles et profanes réservées à la cour; les concerts publics en salles de concert. Telle est l'acception du terme gagaku dans l'ensemble des dictionnaires et encyclopédies de la musique japonaise parus ces trente dernières années ${ }^{5}$. Or ces ouvrages de référence s'appuient de manière uniforme sur la définition contemporaine du gagaku forgée par Tanabe, notamment dans l'article sur le gagaku publié dans le Dictionnaire de la musique de $1955^{6}$, et communément admise depuis par la communauté scientifique. Il n'est pas inutile pourtant de se rappeler ce que fut le gagaku avant cette définition.

Le terme ga-gaku signifie littéralement " musique » (gaku 楽) «légitime », " raffinée » (ga 雅), c'est-à-dire destinée aux rites de la cour ${ }^{7}$. Il apparaît pour la première fois dans les Entretiens de Confucius ${ }^{8}$. Pour le confucianisme en effet, le monarque doit gouverner par «les rites et la musique» (jap. reigaku 礼楽) et non par «la punition et la coercition » (keisei 刑政) ${ }^{9}$. Selon ces idées qui attachent de l'importance aux rites et à la musique comme instruments de la morale politique, la musique idéale est le gagaku comme musique rituelle à la cour ${ }^{10}$. Le terme gagaku ne désigne pas, on le comprend, un certain genre de musique, mais est l'appellation commune à toute musique rituelle jouée à la cour. Il est employé dans ce sens par les dynasties successives en Chine et dans les pays appartenant à la sphère culturelle chinoise. Le mot renvoie donc à un contenu différent selon les régions et les époques ${ }^{11}$.

Dans le Japon $\mathrm{du}^{\mathrm{e}}$ siècle, les échanges culturels avec les Trois Royaumes de Corée et la Chine continentale favorisent l'introduction de diverses musiques du continent, dès lors intégrées dans les rites de la cour impériale et des temples bouddhistes, ce qui leur confère le cachet d'une musique raffinée et officielle. La première occurrence connue du mot gagaku au Japon apparaît en 701, dans un passage consacré à l'office de la musique (Gagaku-ryō 雅楽寮: l'office ministériel du gagaku), qui relève du département des Affaires des nobles (Jibushō 治部省) du ministère des Affaires suprêmes (Daijōkan 太政官) ${ }^{12}$. L'Office, mis en place par les lois connues sous le nom de 《Code de l'ère Taihō" (Taihō-ryō 大宝令), est une école de chant et de danse formant 
les interprètes qui se produisent à la cour impériale. De fait, du viII siècle au début du $\mathrm{x}^{\mathrm{e}}$ siècle, le terme gagaku désigne soit l'office ministériel du gagaku, soit l'ensemble de tous les styles musicaux institutionnalisés par les lois et pratiqués par les membres de cet office ${ }^{13}$ : d'une part «musique japonaise » (yamato-gaku 倭楽) ou en tout cas considérée comme appartenant à un patrimoine peu influencé par les arts continentaux; et d'autre part «musique des Tang» (tō-gaku 唐楽), «musique de Koguryŏ » (kōrai-gaku 高麗楽), « musique de Silla » (shiragi-gaku 新羅楽), « musique de Paekche »(kudara-gaku 百済楽), du nom des trois royaumes de la péninsule coréenne, ainsi que musiques et danses dont on a conscience qu'elles sont venues du continent asiatique $^{14}$.

7 À l'époque de Heian (794-1182), le gagaku prospère dans la culture impériale non seulement comme musique cérémonielle, mais aussi comme divertissement musical. L'empereur lui-même prend part à l'ensemble musical du gagaku. Pour répondre à la demande d'exécution de gagaku, de nouvelles organisations en charge des divertissements musicaux sont fondées, en marge de l'office ministériel du gagaku et

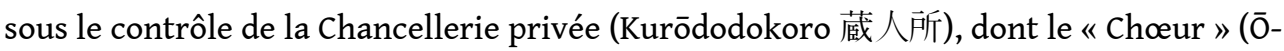
utadokoro 大歌所) et la " Musique » (Gakusho 楽所) ${ }^{15}$. Le premier, à partir du IX siècle, se charge d'exécuter les pièces vocales et à danser « japonaises » que l'Office ministériel du gagaku effectuait jusqu'alors. Désormais, l'office pratique essentiellement la musique " étrangère ", qui est scindée en deux registres au IX siècle : la "musique des Tang $»^{16}$ et la « musique de Koguryŏ $»^{17}$. Cependant, au xe siècle, la « Musique » s'installe et commence à exécuter cette musique " étrangère » en prenant la place de l'office.

(2) rations de l'Office ministériel du gagaku, du "Chœur » et de la "Musique " paraissent à peu près nulles ${ }^{18}$, même si leurs membres sont tous hauts dignitaires ou fonctionnaires à la cour ${ }^{19}$. Parmi eux, on remarque quelques lignées de fonctionnaires subalternes, les familles Ōno 多 ou Koma 狛 par exemple, qui occupent des postes dans la « Musique ». Certaines de ces lignées familiales pratiquent le kagura, genre considéré comme "proprement japonais " à l'époque. Formalisé et pratiqué à date régulière devant le service Intérieur du palais impérial (Naishidokoro 内侍所) à partir de 1002, sous le règne de l'empereur Ichijō, ce rite musical, divertissement offert aux divinités, est l'un des plus importants de la Cour impériale. Avec le déclin de l'ancien système des codes et la sclérose de l'office ministériel du gagaku au $\mathrm{XII}^{\mathrm{e}}$ siècle $^{20}$, le terme gagaku commence à désigner plus précisément la «musique des Tang» et la "musique de Koguryŏ $»^{21}$.

$9 \mathrm{Au}_{\mathrm{XIV}}^{\mathrm{e}}$ siècle, le gagaku résiste un moment à l'arrivée de la nouvelle classe dirigeante militaire. Cependant, durant les guerres civiles d'ōnin, à la fin du $\mathrm{xv}^{\mathrm{e}}$ siècle, les familles de musiciens de gagaku sont contraintes de quitter la capitale impériale dévastée, et le gagaku disparaît presque complètement. À la fin du xvI e siècle, l'empereur ordonne aux familles de musiciens qui ont survécu au temple Kōfuku-ji 興福寺 de Nara et au temple Shitennō-ji 四天王寺 d'Ōsaka, de se rassembler à la cour de Kyōto pour assurer les cérémonies impériales. Ainsi est constituée à nouveau la "Musique», dans les trois villes de Kyōto, Nara et Ōsaka ${ }^{22}$.

On sait que le gouvernement shogunal des Tokugawa encourage durant l'époque d'Edo les études néo-confucéennes. Or les confucianistes attachent de l'importance au gagaku $^{23}$. Dans le même temps, le shogunat préserve l'art et la culture de la cour à la capitale impériale, dans la limite des règles qu'il a toutefois édictées. Il aide financièrement les lignées familiales des musiciens et ordonne à certains d'entre eux de 
monter à la capitale shôgunale et d'y demeurer pour célébrer les rites au mausolée de Tokugawa Ieyasu (Tōshōgū 東照宮) à Nikkō et à Momiji-yama dans le château d'Edo ${ }^{24}$. Ces familles de musiciens de gagaku exécutent essentiellement la «musique des Tang " et la « musique de Koguryŏ ».

11 Au cours de la seconde moitié de l'époque d'Edo, dans un mouvement de restauration des cérémonies impériales, les empereurs qui se succèdent demandent à ce que soient recréées des pièces vocales et à danser «japonaises » déjà disparues à l'époque, telles que l'azuma-asobi 東遊 (divertissement originaire des provinces de l'Est), le yamato-mai 倭舞 (danse de la région du Yamato), ou le kume-mai 久米舞 (danse du clan Kume) ${ }^{25}$. Celles-ci deviendront le gagaku de l'ère Meiji. La plupart des pièces connues comme gagaku à l'époque moderne sont donc des reconstitutions effectuées durant l'époque d'Edo. Ceci n'est pourtant pas allé sans oppositions : Matsudaira Sadanobu, troisième seigneur du fief Shirakawa, s'érigeait en 1829 contre les familles de musiciens et cherchait à redonner au terme gagaku son sens originel de "musique légitime » ou «musique rituelle». Pour lui le gagaku ne pouvait désigner que le kagura et l'azumaasobi, seuls légitimes, parce que "proprement japonais », comme musique rituelle à la cour du Japon ${ }^{26}$.

\section{Le gagaku comme « musique nationale » à l'ère Meiji}

Avec la restauration de Meiji en 1868, l'empereur et le siège du gouvernement quittent Kyōto pour s'installer définitivement dans la capitale de l'Est, Tōkyō, en mai 1869. À partir du 7 novembre 1869, le gouvernement impérial commence à réunir à Tōkyō les familles de musiciens de gagaku qui demeuraient à Kyōto, Nara et Ōsaka ${ }^{27}$. Il leur est demandé d'exécuter en premier lieu du kagura, danse la plus importante à la cour, puis d'autres pièces vocales et à danser « japonaises » (reconstituées à l'époque d'Edo), ainsi que de la «musique des Tang » et de la «musique de Koguryŏ ». L'ensemble fait partie des rites et des cérémonies de la cour impériale reconstruits à la nouvelle cour à Tōkyō ${ }^{28}$. Un département de Gagaku (Gagaku-kyoku 雅楽局) est mis en place au sein du ministère des Affaires suprêmes en novembre 1870, dans une logique de réactivation de l'Office ministériel du gagaku de la cour impériale du viII siècle. Dès 1871 , avec les réformes des statuts des organisations administratives, celui-ci devient section de Gagaku (Gagaku-ka 雅楽課), installée, en 1889, au sein du ministère de la Maison impériale ${ }^{29}$. À la différence des autres arts de la scène traditionnels, le gagaku est la seule musique qui est, dès sa reprise, jouée en présence de l'empereur et institutionnalisée de nouveau par le gouvernement de l'Empire ${ }^{30}$. Le gagaku se voit ainsi redéfini administrativement tel qu'il l'était au $\mathrm{VIII}^{\mathrm{e}}$ siècle, comme toute musique interprétée par la section de Gagaku de la cour, qu'elle relève du répertoire considéré comme «musique proprement de notre pays » (wagakuni koyū no gaku 我邦固有ノ楽), ou comme «musique étant d'origine des Tang ou de Koguryŏ » (tō kōrai den no gaku 唐高 麗伝ノ楽 $)^{31}$.

13 Un autre point est important à souligner : à partir de 1874, les musiciens de gagaku se voient contraints de jouer également de la musique occidentale, puisque cette dernière intervient dans les cérémonies de la famille impériale inspirées du modèle occidental ${ }^{32}$. La musique s'inscrit en effet dans le contexte d'affirmation de la modernité du Japon et de la volonté de faire jeu égal voire de dépasser le niveau de développement culturel des pays occidentaux. Les interprètes de la section de Gagaku forment ainsi le premier 
orchestre occidental du Japon. Quelques musiciens deviennent également chercheurs en musique japonaise et professeurs de musique occidentale au sein de l'Institut de recherches sur la musique (Ongaku torishirabe gakari 音楽取調找) du ministère de l'Éducation ${ }^{33}$.

Dans le déroulement de cette histoire du gagaku à l'ère Meiji, le concept de «musique nationale " (kokugaku 国楽), central lors de «la création des identités nationales en Europe $\aleph^{34}$, joue un rôle majeur. En Europe, le nationalisme musical présent dès la fin du $\mathrm{XVIII}^{\mathrm{e}}$ siècle émerge véritablement au milieu du XIX ${ }^{\mathrm{e}}$ siècle au moment de la création des États-nations ${ }^{35}$. Au Japon, la «musique nationale » va finalement souvent remplir la même fonction que celle attribuée à la musique rituelle dans la pensée confucianiste ${ }^{36}$. Musique nationale et musique rituelle ont en effet en commun à l'époque un même caractère édificateur et moral ${ }^{37}$. Elles sont associées pour la première fois lors de la cérémonie d'inauguration du chemin de fer, le 12 septembre 1872. Pendant que le drapeau national est hissé devant l'empereur Meiji, deux pièces de «musique des Tang» sont jouées par la section de Gagaku: Manzai-raku 万歳楽, à la station de Shinbashi, et Keiun-raku 慶雲楽, à la station de Yokohama. Le gagaku est alors bel et bien désigné par le terme de « musique nationale ${ }^{38}$.

Par ailleurs, dans le mouvement de restauration du pouvoir impérial et de mise en place d'un shintô d'État, les rites de la cour impériale, et par conséquent les musiques interprétées lors de ces rites, sont redéfinis ${ }^{39}$. Parmi ces dernières, le kagura, rituel musical et dansé évoqué dans la mythologie japonaise, ce qui lui confère une origine divine, tend à occuper une place prédominante, et le nombre de représentations de ce registre augmente de façon impressionnante ${ }^{40}$. Parallèlement, en 1878, la participation à l'Exposition universelle de Paris oblige les musiciens de la section du Gagaku à se définir comme interprètes de "musique japonaise $~^{41}$. Il s'agit là d'un point important à relever, car à cette occasion, ils rédigent des partitions et un texte explicatif de leur art, dans ce qui est l'une des premières présentations synthétiques du gagaku ${ }^{42}$. Ils y expliquent notamment que parmi les différents styles de gagaku, le kagura occupe la place la plus élevée en raison de son caractère "proprement japonais ». Un document officiel recommande d'ailleurs, dans le cas où l'on expose des instruments de musique, de disposer les objets relatifs au kagura au premier rang ${ }^{43}$.

Pourtant, plus que les praticiens de la musique, ce sont d'abord des fonctionnaires du ministère de l'Éducation du nouveau gouvernement, tels Megata Tanetarō 目賀田種太 郎 (1853-1926) et Isawa Shūji 伊沢修二 (1851-1917), qui modèlent le discours sur la «musique nationale». Leur concept de «musique nationale» est inspiré par le programme de l'éducation primaire des États-Unis, fondé en 1838 à Boston sur les théories du pédagogue suisse Johann Heinrich Pestalozzi (1746-1827). De fait, le principal but de la musique scolaire aux États-Unis est alors de faire apprendre aux enfants qui ne parlent pas anglais le langage et la prononciation authentiques à l'aide du chant, composante de la "musique nationale»; ceci dans le contexte politique de construction d'une nation dans laquelle le nombre d'immigrants augmente ${ }^{44}$. Construire une nation moderne par une "musique nationale " répond tout à fait aux espérances de Megata et d'Isawa, justement envoyés à Boston pour des recherches sur l'éducation primaire par le ministère de l'Éducation en 1875.

17 Or, ces derniers sont loin de mettre le gagaku au centre de leur réflexion. Ils proposent en effet, après leur retour des États-Unis, de constituer le répertoire de cette « musique nationale » de façon très large ${ }^{45}$ : 


\begin{abstract}
La musique nationale doit être constituée des chansons et des mélodies nationales que tout membre du peuple japonais peut, en tant que tel, qu'il soit aristocrate ou roturier, chanter et jouer, sans distinction entre le raffiné et le vulgaire : il s'agit de puiser dans les œuvres de qualité propres à notre pays, dans son passé comme dans son présent, mais aussi, si besoin, dans celles de la musique européenne.

国学（=楽）トハ我国古今固有ノ詞歌曲調ノ善良ナルモノタ尚研究シ、其ノ足 ラザルハ西洋ニ取リ、貴賤二関ハラズ又雅俗ノ別ナク誰ニテモ何レノ節ニテモ

日本ノ国民トシテ歌フベキ国歌、奏ヅベキ国調ヨ興スヨ言フ
\end{abstract}

Bref, pour les auteurs, la «musique nationale » renvoie à un répertoire que le peuple japonais actuel doit inventer, et non pas au gagaku raffiné du passé impérial ni d'ailleurs à la musique populaire ou à la musique européenne. Cette «musique nationale », il faut la créer en cherchant au contraire les meilleurs éléments de ces différents registres. L'idéal des auteurs se manifeste dans les trois volumes du Recueil de chants pour l'école primaire (Shōgaku shōka shū 小学唱歌集) publiés entre 1881 et 1884 par l'Institut de recherches sur la musique du ministère de l'Éducation. Il est à noter que ce recueil est édité pour enseigner la gamme occidentale à sept tons : l'heptacorde. Il s'appuie sur les exercices du manuel de musique Primary of First National Music Reader (Manuel élémentaire du premier lecteur de la musique nationale) de l'éducateur musical de Boston Luther Whiting Mason (1828-1896), qui a été invité au Japon par Isawa, alors directeur de l'Institut de recherches sur la musique ${ }^{46}$. Le rapport d'activité de cet institut insiste par ailleurs sur la grande ressemblance entre l'heptacorde du gagaku japonais en ce qui concerne la musique «de qualité propre à notre pays » et celui de la musique grecque ancienne pour " la musique européenne $»^{47}$. On comprend ici la vertu éducative que devait posséder le répertoire d'une musique en phase avec l'émergence d'une nouvelle nation.

Par ailleurs, malgré l'espoir de la section de Gagaku de constituer son art en «musique nationale », la définition - généralement admise jusqu'à l'époque d'Edo - selon laquelle le gagaku est une musique d'origine chinoise et coréenne, va largement subsister. C'est le cas, par exemple, dans le Nihon jisho genkai 日本辞書言海, célèbre dictionnaire compilé par Ōtsuki Fumihiko 大槻文彦 en 1879, dont l'avis sera repris par presque tous les autres dictionnaires de l'ère Meiji. Le gagaku suscite d'ailleurs de franches oppositions. Ainsi, un article anonyme intitulé «La fondation de la musique nationale et l'Association du gagaku ", publié dans la revue littéraire de l'Université impériale de Tōkyō, explique-t-il la raison pour laquelle le gagaku ne devrait pas être la «musique nationale $\aleph^{48}$. Il évoque trois causes rédhibitoires: tout d'abord, c'est une musique importée de l'étranger et réservée à la haute société; deuxièmement, elle n'est pratiquée que dans les villes; enfin, elle est loin d'avoir constitué le seul genre de musique au cours de l'histoire japonaise, le peuple japonais dans son ensemble s'étant intéressé à bien d'autres genres. On voit donc que l'idée du gagaku comme "musique nationale » ne fait pas l'unanimité, ou plus exactement, qu'on peut vouloir trouver d'autres fondements que l'ancienneté du gagaku au concept de « musique nationale ».

On prêtera une attention particulière ici à une logique que l'on pourrait dire « romantique » et qui se caractérise par l'importance accordée aux notions de peuple et de tradition: ne peut être considérée comme musique nationale une musique qui n'a pas été jouée, avant, par l'ensemble de la nation. Ce mode de pensée, consistant à idéaliser un passé perdu qui serait détenu par l'ensemble de la communauté nationale, est identique à celui qui anime ceux qui, à la même époque, s'intéressent aux «chants folkloriques ». 
21 Il y a en effet au Japon un mouvement littéraire inspiré par le romantisme allemand visant à collecter dans tout le pays des chants populaire et à en composer de nouveaux. Le but des partisans de ce mouvement est de renforcer l'identité nationale au moyen de chants faisant partie de l'identité du terroir ${ }^{49}$. Le terme japonais de min.yō 民謡 (《 chant du peuple»), forgé par Mori ōgai pour traduire le terme allemand «Volkslied » ${ }^{50}$, est définitivement adopté suite à son utilisation par Ueda Bin 上田敏 (1874-1916), professeur de littérature anglaise, traducteur et poète ${ }^{51}$. Le fait que l'un et l'autre s'intéressent aux chants et chansons populaires montre à quel point ceux-ci représentent un sujet de réflexion de première importance pour les intellectuels de la modernité japonaise.

Au début du $\mathrm{xx}^{\mathrm{e}}$ siècle, le Japon, vainqueur de la «Grande Russie » au terme de la guerre russo-japonaise (1904-1905), se met à relativiser la primauté de la modernisation «à l'occidentale » et commence à rechercher une modernité qui lui serait propre. Dans ce contexte, la discussion autour des « chants folkloriques » s'étend à la pensée musicale du début $\mathrm{du} \mathrm{xx}^{\mathrm{e}}$ siècle, dans la continuité du discours sur la musique nationale. Ceux-ci deviennent aussi un thème important dans le département de "Littérature nationale » à l'Université impériale de Tōkyō où Shida Yoshihide 志田義秀 (1876-1946), étudiant en littérature japonaise ${ }^{52}$, publie une série d'articles qui les promeut au centre de l'esprit romantique ${ }^{53}$.

Son travail, qui englobe dans un même ensemble tous les chants "proprement japonais » tels que les pièces du saibara considérées depuis le $\mathrm{IX}^{\mathrm{e}}$ siècle comme des chants de palefreniers ${ }^{54}$, va permettre aux musiciens de la section de Gagaku du ministère de la Maison impériale de faire valoir qu'une partie de leur répertoire, constituée de chants "proprement japonais", est à considérer comme "musique folklorique ", c'est-à-dire propre au peuple japonais. Ils contrent ainsi les critiques arguant que le gagaku étant venu de l'étranger et ayant été réservé à une élite aristocratique, il ne pouvait être pris comme « musique nationale ».

Shiba Fujitsune 芝葛鎮 (1849-1918), chef musicien de gagaku de la cour à la fin de l'ère Meiji, définit de nouveau le terme gagaku dans le Grand dictionnaire de l'histoire du Japon, en distinguant les «pièces vocales" (utaimono ou utamono 歌物) des "pièces instrumentales » (kangen 管絃) et en intégrant les chants folkloriques dans les «pièces vocales $\aleph^{55}$. Cette définition sera régulièrement réemployée, par exemple par Tōgi Tetteki 東儀鉄笛 (1869-1925), ex-musicien à la cour et enseignant la musique occidentale à l'Université de Waseda, dans l'édition de ses cours donnés à l'université ${ }^{56}$.

\section{Tanabe Hisao : de l'acousticien au musicologue}

Si le gagaku est décrit comme "musique nationale » ou "musique japonaise » avant tout par les musiciens à l'ère Meiji, à partir de l'ère Taishō (1912-1926) ce sont les scientifiques qui vont prendre le relais, notamment, nous l'avons dit, sous l'impulsion de Tanabe Hisao.

Tanabe Hisao est né le 16 août 1883 à Tōkyō. Après la mort de sa mère en 1892, il est adopté par l'un de ses parents, Tanabe Teikichi 田辺貞吉, directeur général de la Banque Sumitomo. Un violon de la maison Suzuki donné par son beau-père permet à Tanabe de travailler la musique à partir du moment où il commence à s'intéresser à cet instrument, dans la classe de musique du collège. Il poursuit l'étude du violon au cours 
du premier cycle d'études supérieures de la Faculté de sciences et de technologie du Premier Lycée (Ichikō 一 高) à Tōkyō. Là, il découvre des livres de théorie musicale allemande grâce à la rencontre avec de grands connaisseurs du domaine musical tels qu'Otsukotsu Saburō 乙骨三郎 (1881-1934), qui enseignera l'esthétique et l'histoire de la musique à l'École nationale de musique de Tōkyō, ou Ishikura Kosaburō 石倉小三郎 (1881-1965), auteur de la première Histoire de la musique européenne (Seiyō ongaku shi 西 洋音楽史) $\mathrm{au} \mathrm{Japon}{ }^{57}$.

Son environnement familial n'est pas négligeable dans son parcours: Tanabe a ainsi très tôt accès à une collection de livres de vulgarisation musicale publiés aux ÉtatsUnis, tel celui de Henry Edward Krehbiel, How to Listen to Music: Hints and Suggestions to Untaught Lovers of the Art (1897), ou celui de William James Henderson, How Music Developed: A Critical and Explanatory Account of the Growth of Modern Music (1898) ${ }^{58}$. Il possède également un gramophone avec une importante collection de disques de musique japonaise et occidentale appartenant à son beau-père et à lui-même. Nul doute que ceci contribue à sa réussite. Parvenu à intégrer la prestigieuse Université impériale de Tōkyō, Tanabe sort major de sa promotion au département de Physique en 1907. Son mémoire de fin d'études, intitulé Études acoustiques sur les instruments de musique à vent (Kangakki no onkyōgaku teki kenkyū 管楽器の音響学的研究, 1907) traite de la Théorie physiologique de la musique fondée sur l'étude des sensations auditives de l'allemand Hermann von Helmholtz (1821-1894) paru en $1863^{59}$.

$\mathrm{Au}$ moment où Tanabe entreprend ses études sur la musique, un certain nombre de physiciens japonais travaillent déjà dans le domaine musical. Ainsi Tanaka Shōhei 田中 正平 (1862-1945), docteur ès science et acousticien, qui est allé en Allemagne sur ordre du ministère de l'Éducation en 1884 et a étudié sous la direction de Helmholtz à l'Université de Berlin pendant environ quinze ans. Après son retour au Japon en 1899, inspiré par les conseils de Helmholtz, il établit, en 1905, l'Institut de recherches sur la musique nationale (Hōgaku kenkyū-jo 邦楽研究所), afin d'étudier la «musique japonaise " en la notant et la transcrivant dans le système de notation occidentale ${ }^{60}$. Tanabe rejoint cet institut dès sa première année de doctorat de sciences à l'Université Impériale de Tōkyō, en 1907, pour commencer l'étude de la musique japonaise sous la direction de Tanaka. C'est là qu'il débutera sa carrière de chercheur. On peut relever que sous l'impulsion du gouvernement japonais de Meiji nombreux sont les chercheurs et universitaires de la génération de Tanaka qui sont partis étudier en Europe et aux États-Unis. Tanabe, lui, comme nombre de scientifiques de son âge, fera toutes ses études et sa carrière au Japon.

\section{L'histoire de la musique japonaise dans une perspective évolutionniste}

Sous l'influence de Helmholtz, l'étude de la musique japonaise de Tanabe accorde une grande importance à une approche relevant des sciences physiques et naturelles. En ce sens, les travaux de Tanabe apparaissent comme une variante de la musicologie européenne du début du $\mathrm{xx}^{\mathrm{e}}$ siècle, elle aussi très déterminée par l'œuvre de Helmholtz. À partir de 1909, Tanabe écrit plusieurs articles dans la Revue des sciences et des arts orientaux (Tōyō gakugei zasshi 東洋学芸雑誌), concernant l'harmonie et la gamme chinoises comme origines du gagaku. Il poursuivra cette étude par une comparaison des gammes occidentale, chinoise et japonaise, dans son ouvrage Principes musicaux 
considérés du point de vue des sciences modernes (Saikin kagakujō yori mitaru ongaku no genri 最近科学上より見たる音楽の原理), publié par Uchida rōkaku ho 内田老鶴圃 en 1916.

Tanabe Hisao 田辺尚雄

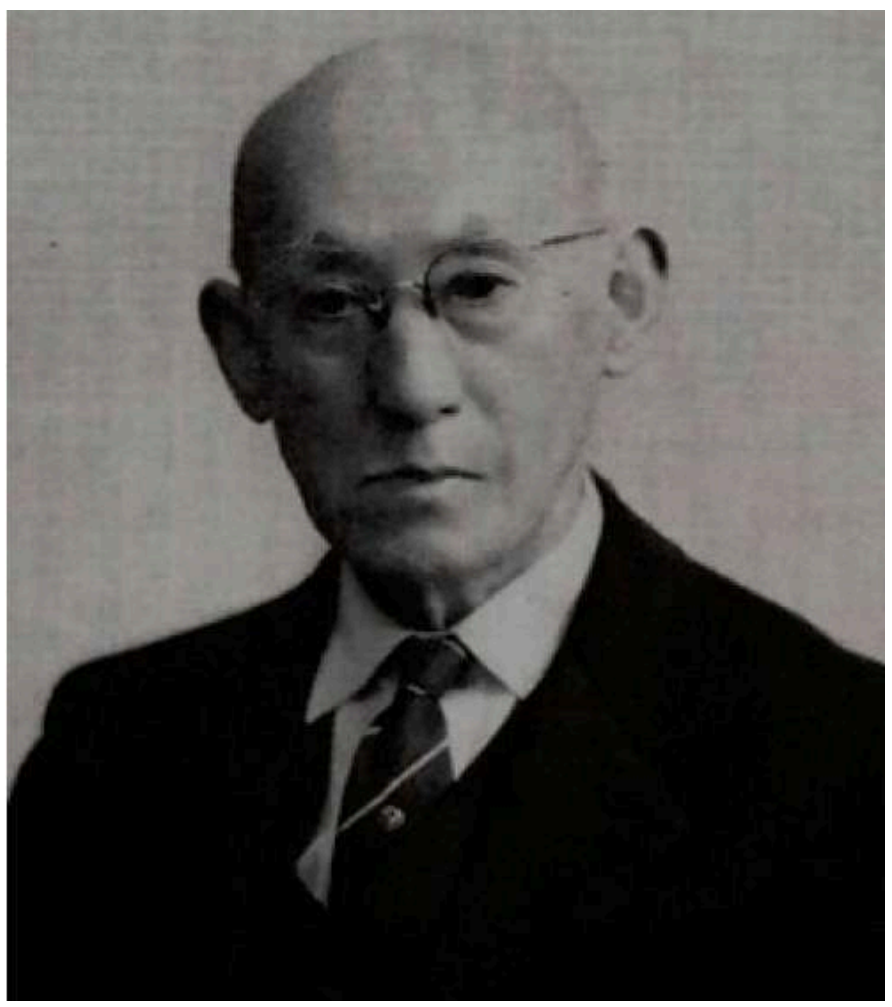

http://22982298.blog.fc2.com/blog-category-29.html (25 mai 2014).

Néanmoins, la conception de l'histoire de la musique japonaise qui prévaut au Japon à cette époque rend particulièrement difficile toute adaptation de la musicologie occidentale. En effet, en raison de l'absence de partition fixée, d'une moins grande importance accordée à l'harmonie et d'une certaine fixité au cours de l'histoire, la musique japonaise est perçue comme une musique ne pouvant s'inscrire dans la conception évolutionniste de l'histoire de la musique qui domine chez Helmholtz, et d'une manière générale en Occident. Ainsi, les arts japonais, considérés alors comme "nationaux », tels que le gagaku, le nō, le kabuki, parce que présentés comme étant restés immuables depuis longtemps, ne sauraient apparaître comme le dernier résultat d'une longue évolution historique, et constituent, en quelque sorte, un contre-exemple à la pensée évolutionniste. On peut certes ranger la musique dans la catégorie des sources historiques, comme le fait Konakamura Kiyonori 小中村清矩 (1821-1895) en 1888, dans la première histoire de la musique japonaise ${ }^{61}$, mais l'absence de mise en perspective de cette conception historiographique rend impossible de décrire la musique comme le fait l'histoire européenne, c'est-à-dire comme un phénomène qui évolue des temps les plus anciens jusqu'à nos jours.

Dans ce contexte, Tanabe doit faire face à une contradiction: comment, en effet, soutenir d'un côté la conception d'une musique qui, pour être nationale, doit être fixe et immuable et inscrire, de l'autre, la musique dans une approche évolutionniste en conformité avec les canons scientifiques de son époque? Il tente de résoudre le paradoxe dans ses Conférences sur la musique japonaise (Nihon ongaku kōwa 日本音楽講話) 
publiées par Iwanami shoten en 1919, son premier livre sur l'histoire de la musique japonaise considérée d'un point de vue évolutionniste. Par rapport aux travaux précédents, l'histoire de Konakamura déjà citée par exemple, qui juxtaposaient simplement les divers types de musique d'après ce qu'en disaient les sources historiques, Tanabe propose de considérer l'histoire de la musique japonaise comme un processus évolutif de "japonisation » progressive de la musique savante importée de l'extérieur. Dans cette approche, il doit insister sur le fait qu'il y a coexistence de deux types contradictoires de kagura: un kagura "peu développé »(mikaiteki 未開的) et "primitif»(genshiteki 原始的), remontant aux origines mythiques du Japon avant l'importation du gagaku étranger; et un kagura plus «formel» (keishikiteki 形式的) et 《artistique » (geijutsuteki 芸術的), recréé au Moyen Âge d'après le gagaku étranger certes, mais selon un « esprit proprement japonais» (nihon koyū no seishin 日本固有の 精神).

Parallèlement à Tanabe, et bien qu'étant dans l'incapacité de trouver des traces de sa pratique avant le Moyen Âge (l'époque de Heian), la section de Gagaku de la cour insiste sur le fait que le kagura qu'elle exécute est lié directement à l'époque ancienne. Cette affirmation dépourvue de preuves ne satisfait toutefois pas les aspirations scientifiques de Tanabe. Dans la perspective évolutionniste qui est la sienne, en effet, la forme la plus élevée de gagaku n'est pas à rechercher dans ses expressions primitives, mais bien dans celles qui sont issues des importations de l'étranger revisitées par l'esprit japonais au Moyen Âge :

Le kagura issu du Moyen Âge n'est pas du tout celui des temps anciens, c'est un nouvel art totalement créé au second tiers de l'époque de Heian, avec une forme chinoise et l'esprit japonais.

後世の神楽は平安朝の中期に至つて支那の形式を参考し之れに日本の精神を加

へて全く新たに制定した新芸術であつて上世の神楽とは全然別ものである。62

Pour lui, c'est l'application d'un "esprit proprement japonais» qui a permis l'assimilation de la musique chinoise "savante» au profit de l'édification d'une musique "japonaise", à l'image des processus d'emprunts et d'assimilation de la musique occidentale à l'époque Meiji. Et c'est l'affirmation d'un tel esprit et d'un tel procédé qui rend possible la revendication d'une musique proprement nationale, pouvant rivaliser avec la musique occidentale. Pourtant, si ceci est l'objectif affiché, Tanabe dresse le constat qu'en l'état l'égalité n'est pas encore possible. Si elle peut bien être vue comme le résultat d'un processus évolutif long, il manque encore à la musique japonaise une dernière caractéristique :

La musique japonaise n'est pas de taille à lutter contre la musique occidentale au niveau de la rationalité. Elle est incomparablement moins méthodique que la musique de Beethoven. Cependant, cela ne diminue en rien la valeur de la musique japonaise.

理性的に於ては日本音楽は到底西洋音楽に及ばない。日本音楽は如何に之を弁 護せんとしても其組織に於て到底ベートーフェンの音楽に比局されるものはな

い。然しその事は少しも日本音楽の価値を下げるものではない。63

On voit ici ce qui pour Tanabe peut apparaître comme une faiblesse « rationnelle » de la musique japonaise par rapport à la musique occidentale, c'est-à-dire l'absence de notation fixée, sa moindre richesse harmonique, etc., mais avec dans le même temps, l'affirmation de la valeur de cette musique japonaise notamment parce qu'elle est musique nationale créée par un « esprit proprement japonais ». 


\section{Conserver par le disque}

les conceptions musicales de Tanabe. Le Japon partage en effet avec les pays occidentaux une histoire commune de la machine parlante et de sa diffusion de plus en plus massive auprès du public, ceci dès l'invention de l'enregistrement sonore (en 1877), puis du phonographe Edison-type (le cylindre de cire, en 1878), et du gramophone d'Émile Berliner (le disque plat, en 1887) ${ }^{65}$. En 1920, Tanabe est déjà célèbre pour sa connaissance sans égale de tout ce qui concerne le gramophone et les disques. Il a d'ailleurs réalisé à travers le Japon une tournée de conférences musicales illustrées par des enregistrements sur disques, d'où son surnom de «montreur de disques » (chiku-ben 蓄弁) ${ }^{66}$. Dès 1920, il est conseiller auprès de la rédaction de la revue Musique et Machines parlantes (Ongaku to chikuonki 音楽と蓄音器) ${ }^{67}$. En 1923, il deviendra l'un des principaux membres du Comité de sélection des disques au ministère de l'Éducation. Ses guides discographiques tels que la Vie des contemporains et la Musique (Gendaijin no seikatsu to ongaku 現代人の生活と音楽) de 1924, ou Guide pour apprécier chez soi les grands morceaux de musique (Katei de ajiwau beki rekōdo meikyoku kaisetsu 家庭 で味ふベきレコード名曲解説) de 1925, publiés dans le but d'éduquer le goût de la classe moyenne des villes apparue à la «belle époque» japonaise dans les décennies 1910-1920, rencontreront un grand succès. (1888-1981), collecteur de musique folklorique par l'enregistrement et chef de l'« Association de la conservation de la musique classique [du Japon] » (Kokyoku hozon kai 古曲保存会). Celui-ci demande à Tanabe de produire les disques et de rédiger le livret accompagnateur. Tanabe sollicite à cette fin la section de Gagaku de la cour impériale où il était chargé de donner des cours de théorie musicale et d'histoire de la musique occidentale ${ }^{68}$. Selon Tanabe, huit musiciens acceptent volontiers la proposition. Tanabe et Machida fixent les conditions suivantes : jouer deux heures trois fois par jour, moyennant une rétribution de dix yens par jour et par personne ${ }^{69}$. Les morceaux de musique de gagaku sont enregistrés sur vingt disques, selon un ordre qui restitue la chronologie évolutionniste de Tanabe :

1. Musique de la haute antiquité spécifique au Japon (nihon koyū no jōko ongaku 日本固有の上古 音楽) : deux disques.

2. Musique de Koguryŏ (koma-gaku 高麗楽) : deux disques plus une face.

3. Musique de Chine (shina no ongaku 支那の音楽) : quatre disques plus une face.

4. Musique des barbares de la Chine de l'Ouest (shina seibu no igaku 支那西部の夷楽) : un disque plus une face.

5. Musique de l'Inde et de l'Asie centrale (indo oyobi chūō ajia no ongaku 印度及中央アジアの音 楽) : cinq disques.

6. Musique presque complètement recréé au Japon (nihon de daibubun kaisakushita gakkyoku 日 本で大部分改作した楽曲) : un disque plus une face.

7. Saibara (催馬楽 《 poèmes chantés en japonais ») : deux disques. 
8. Rōei (朗詠 « poèmes chinois chantés à la japonaise ») : un disque $\mathrm{e}^{70}$.

38 Ainsi, Tanabe arrive à illustrer sa théorie évolutionniste grâce à l'enregistrement du gagaku sur disque. Le gagaku est en effet défini "dans l'ordre de l'évolution » ${ }^{71}$ que reflète l'ordre des disques. La matérialité du disque donne à écouter le gagaku en fixant son ordre d'évolution et construit de la sorte une linéarité historique accompagnée d'une unité géographique :

1. De l'Antiquité à l'époque de l'impératrice Suiko (règne 593-628), musique propre au Japon : kagura, kume-uta, kishi-mai 吉志舞, azuma-asobi, yamato-mai, etc.

2. De l'époque de l'impératrice Suiko au premier tiers de l'époque de Heian (794-1185), musique importée d'autres pays de l'Asie : chōsen-gaku 朝鮮楽 (musique de Chosŏn [Corée]), shina-gaku 支那楽 (musique de Chine), indo-gaku 印度楽 (musique de l'Inde), nihon de maneta gaku 日本で真似た楽 (musiques créées au Japon, mais imitées de celles-ci).

3. Du second tiers à la fin de l'époque de Heian, musique fusionnant répertoire japonais et style importé des autres pays : saibara, rōei et imayō 今様 ${ }^{2}$.

Il catégorise de la sorte le gagaku en trois genres, qui sont également perçus comme trois étapes de son évolution et peuvent légitimer le gagaku comme musique originelle du Japon, ce qui s'accorde avec l'idéologie impériale de son époque. Sa position rejoint également l'opinion des musiciens de la section de Gagaku qui placent le kagura "proprement japonais» au sommet du gagaku (même si on a vu précédemment le désaccord de Tanabe avec l'hypothèse de la filiation du kagura de l'époque ancienne émise par les musiciens). Sa théorie fait donc référence au début de l'histoire japonaise, et le gagaku devient ainsi le symbole à la fois de la spécificité du Japon, et de son évolution.

La collection explicite d'autre part le rôle central que joue le disque dans les conceptions musicologiques de Tanabe et l'importance qu'il accorde à ce média comme moyen d'éducation ${ }^{73}$ et d'élaboration du patrimoine.

\section{D'une musique nationale à la musique de la « Grande Asie orientale »}

En janvier 1920, Tanabe reçoit la bourse de la Fondation Keimei-kai 啓明会 pour ses 《études scientifiques sur la théorie de la musique orientale " ${ }^{74}$. Après avoir placé, dans un premier temps, le gagaku de la cour aux origines de l'histoire du Japon, il l'y situe cette fois aux origines du monde. En novembre 1920, à l'occasion d'une enquête sur les instruments de musique conservés au Trésor impérial (Shōsō-in 正倉院) à Nara, il avance notamment l'hypothèse que l'origine du kugo 笻篌, harpe de l'ancien gagaku, pourrait remonter à l'époque de l'Assyrie ancienne ${ }^{75}$. Cet instrument de musique permet à Tanabe d'élargir son champ d'études à la fois chronologiquement et géographiquement.

Ses premières recherches sur «la musique orientale $»^{76}$, menées en avril 1921 dans la Corée sous administration japonaise, ont pour but, d'une part de vérifier cette hypothèse de l'origine du kugo et d'autre part de sauvegarder le gagaku de l'ancienne cour de Corée de la dynastie Chosŏn (1392-1910) ${ }^{77}$. L'initiative en revient au gouvernement général de Corée (japonais donc), qui demande à la section de Gagaku de la cour du Japon de sauver le département de Gagaku de l'ancienne cour de Corée. Ue Sanemichi 上眞行 (1851-1937), alors chef de la section et professeur à l'École nationale 
de musique de Tōkyō, transmet cette demande à Tanabe. Dès réception, celui-ci part en Corée, apportant avec lui la collection de disques de gagaku qu'il vient de publier. Pendant son séjour, il donne plusieurs conférences sur le gagaku japonais en sensibilisant l'auditoire grâce à ses enregistrements. L'administration coloniale du pays lui donne toute facilité pour travailler dans de bonnes conditions et étudier comme il l'entend. Tanabe affirmera que ces recherches, qui le conduisent à enregistrer, photographier, filmer, transcrire dans le système de notation occidentale, collecter des instruments de musique, diffuser à la radio et inspirer des recherches sur le gagaku coréen en Corée, ont contribué à sauvegarder cet art en tant que patrimoine ${ }^{78}$. Mais à l'évidence, dans le même temps, pour le gouvernement général japonais de Corée, le fait de sauvegarder le gagaku de la dynastie Chosŏn a une visée de propagande culturelle destinée à justifier l'annexion et à gagner les faveurs de la cour de la dynastie Chosŏn, tout particulièrement après le mouvement d'indépendance coréen du San'ichi undō (Samil Undong) 三一運動 en $1919^{79}$. On peut remarquer que la Corée joue deux rôles dans la réflexion sur le gagaku. À l'origine de certaines des pièces les plus anciennes et donc du début de cet art au Japon, c'est également, au début du xx siècle, pour le Japon devenu puissance coloniale, un laboratoire offert aux meilleurs des spécialistes pour expérimenter les techniques d'enregistrement les plus modernes et les théories les plus novatrices.

Si la Corée est la première de la liste, les recherches de Tanabe sur «la musique orientale » se succèdent rapidement ensuite dans les territoires colonisés ou gouvernés par le Japon: Taïwan au printemps 1922, Okinawa en été 1922, Chine au printemps 1923, péninsule de Sakhaline et îles Kouriles en été 1923, Mandchourie au printemps 1924, îles Carolines en été 1934, Mandchourie de nouveau en automne 1940. En Chine et en Mandchourie, il fait plus précisément des recherches sur le gagaku ancien et donne des conférences ponctuées par l'écoute de disques de gagaku japonais. L'implication politique de son travail est pour lui une évidence. Il raconte ainsi que la manifestation chinoise contre le Japon pendant le "jour de l'humiliation nationale $»^{80}$ du 9 mai 1923 à Beijing s'est arrêtée grâce à sa conférence intitulée «La valeur de la musique chinoise » à l'Université de Beijing, conférence à l'occasion de laquelle il avait affirmé que le Japon restituerait à la Chine le gagaku, qui y a disparu, mais qui fut protégé à la cour du Japon, si elle remerciait la famille impériale du Japon pour la protection du gagaku ${ }^{81}$. Cette même conférence aurait d'ailleurs inspiré, toujours selon Tanabe, des recherches sur la «musique nationale » en Chine et en Corée ${ }^{82}$.

Les réflexions de Tanabe sur la musique orientale sont réunies dans son Étude sur la musique japonaise, parue en 1926, qui «donne une interprétation révolutionnaire de l'histoire de la musique japonaise en s'appuyant largement sur l'étude comparative de la musique orientale ${ }^{83}$. En 1929, ses Études sur la musique orientale lui valent le Prix de l'Académie impériale (Teikoku gakushiin shō 帝国学士院貝) ${ }^{84}$, et l'année suivante, il devient le premier chargé de cours en histoire de la musique japonaise à l'Université impériale de Tōkyō. Il occupera également le poste de président de la Société orientale de Musique, fondée en 1936 par l'un de ses élèves, Kishibe Shigeo 岸辺成雄 (1912-2005), historien de l'Asie orientale, et Iida Tadasumi 飯田忠純 (1898-1936), historien de l'Islam ${ }^{85}$.

45 Ainsi, le cadre des recherches scientifiques sur la « musique orientale » est-il prêt. Dans l'article inaugural du premier numéro de la revue de la Société orientale de musique de 
Tōkyō, en 1937, Tanabe souligne l'importance du fait que la musique orientale soit étudiée par les Orientaux eux-mêmes ${ }^{86}$ :

Comme le dit le proverbe « ex oriente lux » (« De l'Est vient la lumière »), la brillante culture de l'Occident moderne a été formée à partir d'éléments originellement importés d'Orient, que l'Occident a accumulés et développés pendant une longue période avant de donner naissance à des fleurs exubérantes et de riches fruits.

Cependant, après être entrée dans le $\mathrm{xx}^{\mathrm{e}}$ siècle, cette brillante culture occidentale moderne en est arrivée à montrer des signes de stagnation et de décadence. [...] Le soleil qui se lève à l'Est est en train de se coucher à l'Ouest.

Aujourd'hui, le monde attend à nouveau la lumière de l'Orient. C'est la raison pour laquelle de nombreux Occidentaux ont depuis peu déployé beaucoup d'efforts dans les recherches sur la culture orientale. Cependant, ces dernières doivent être menées par les Orientaux eux-mêmes. Allons! Il est temps que les Japonais, en lesquels l'Orient met tant d'espoir, prennent l'initiative des études sur la culture orientale!

『光は東方より』といふ浐があるが、西洋近代の燦然たる文化はもと東洋より

輸入されたもので、それを長年月に捗って蓄積発展せしめた結果、近代に 至って燗漫たる花を開き、豊熟せる果を央らせたものであつた。

然るに此の燦然たる西洋近代の文化も、今世紀に入って漸く沈滞し、腐敗する の傾向を示すに至った。[...] 東方より出でたる太陽は今や正に西方に没せんと しつっある。

藥に於て今や世界は再び東方よりの光を熱望して居る。斯くして最近多くの西 洋人は多大の努力を東洋文化の研究に致して居る。然しながら東洋の研究は東 洋人の手によってなされなければならぬ。今や東洋の言望を担ふ我が日本人は 世界に率先して東洋文化の研究に其力を尽さなければならない。

\section{« Kugo du Shōsō-in » (Shōsō in no kugo 正倉院の筧筃)}

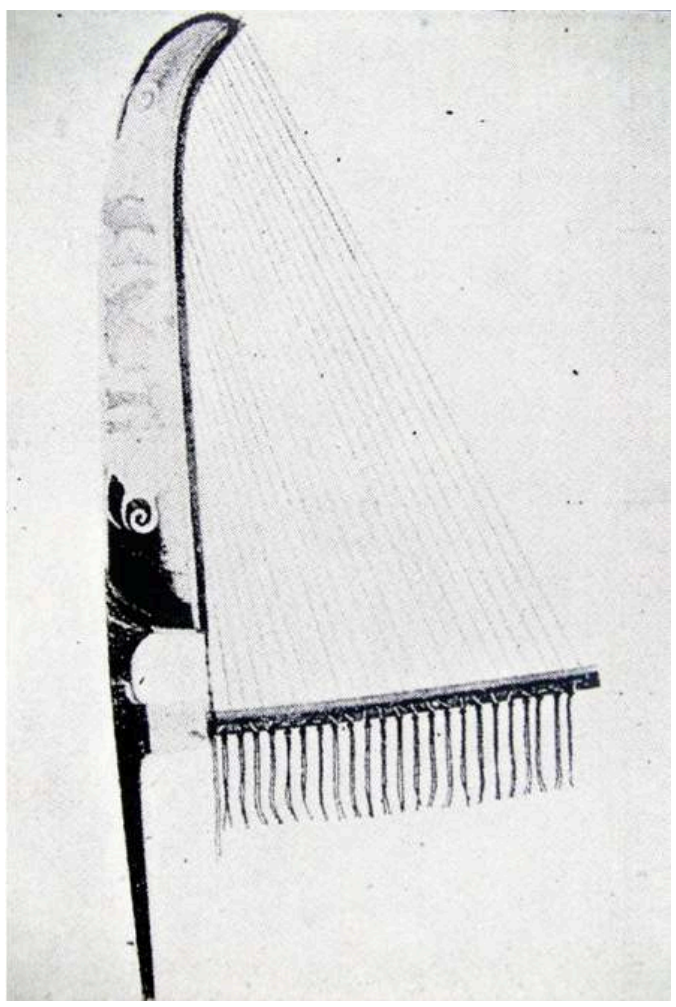

《Kugo du Shōsō-in » (Shōsō in no kugo 正倉院の箜篌), désignation de Tanabe ; Ue Sanemichi 上眞行, Ōno Tadamoto 多忠基 et Tanabe Hisao, Shōsō-in gakki no chōsa hōkoku 正倉院楽器の調査報告 (Rapport de recherche sur les instruments de musique du Shōsō-in), Tōkyō, Teishitsu hakubutsukan gakuhō 帝室博物館学報, no 5, 1921 (annexe illustrations). 


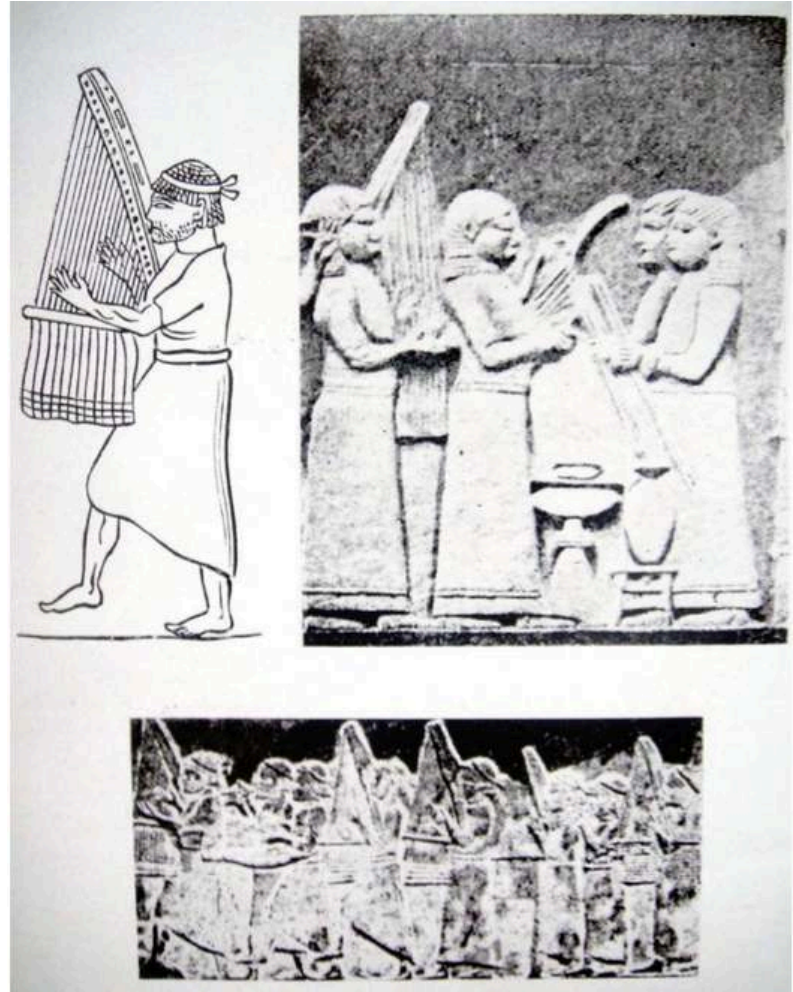

« Kugo de l'Assyrie » (Asshiria no kugo アッシリアの箜篌), désignation de Tanabe ; Ibid.

Mais si Tanabe affirme que les «Orientaux» doivent prendre en charge les études sur l'Orient, il ne dit pas comment ces derniers doivent faire pour se réapproprier cet objet d'étude $^{87}$. Dans un premier temps donc, il va s'agir, pour Tanabe comme pour les musicologues japonais, de redéfinir et de préciser ce qu'est la sphère musicale de l'«Orient» par rapport à la définition préexistante qu'en donne la musicologie occidentale. En effet, l'étude de l'Orient a été inventée en Occident, et le terme même de «musique orientale» a toujours renvoyé à une "musique non occidentale», indifférenciée, sans spécificités géographiques et culturelles.

Tanabe propose une première définition en publiant, en décembre 1941, une compilation de dix disques de musiques d'Asie intitulée Musique de l'Asie orientale (Tōa no ongaku 東亜の音楽) chez Columbia-Nipponophone. Cela n'est pas la première tentative de compilation de la musique asiatique. En 1928, une Musik des Orients avait été éditée en douze disques par Erich von Hornbostel (1877-1935), de l'Université de Berlin, chez Parlophon-Odéon ${ }^{88}$. Tanabe critique vivement la compilation de Hornbostel, selon lui trop "exotique ", et défend la nécessité d'" une compilation de musique orientale authentique ${ }^{89}$. "Authentique " étant entendu ici au sens d'une anthologie réalisée par des «Orientaux ». Il complète sa première tentative l'année suivante, en 1942, avec la Collection de musique de la Grande Asie orientale (Daitōa ongaku shūsei 大東亜音楽集成), éditée par la Société orientale de musique sur trente-six disques 78 tours de la compagnie Japan Victor Records, et avec la Musique du sud [de l'Asie] (Nanpō no ongaku 南 方の音楽), six disques 78 tours de Columbia-Nipponophone ${ }^{90}$. Les explications et commentaires qui accompagnent ce travail revêtent un caractère scientifique marqué, qui n'est pas sans évoquer les archives phonographiques constituées par les Universités 
de Berlin et de Vienne, ou par le musée de l'Homme de Paris, qui ont posé les bases d'une recherche scientifique dans le domaine de la "musicologie comparée " (alors « ethnomusicologie ») au début du xxe siècle.

Le point le plus important est que la musique japonaise ne figure nulle part dans ces trois collections de musiques de la Grande Asie orientale. Et même si Tanabe ne le dit pas explicitement, par "Japon», on entend ici non seulement l'archipel, mais également la Corée et Taïwan, considérés comme faisant partie intégrante du pays. Dans le livret explicatif de la Musique de l'Asie orientale, Tanabe en précise la raison ${ }^{91}$ :

Notre pays fait partie de l'Asie orientale du point de vue géographique. Et la musique japonaise fait partie de l'histoire de la musique orientale du point de vue historique. Cependant, il ne faut pas s'arrêter à la surface des choses [...] parce que le Japon est au cœur de l'Asie [...]. Toutes les routes de la culture, des temps anciens à nos jours, ont donc convergé vers notre pays, toutes ces cultures ont été conservées, unifiées, assimilées et recréées par le génie japonais. Ainsi, une culture proprement japonaise a vu le jour. Aujourd'hui, la culture occidentale qui parvient au Japon contribue elle aussi à la création de la culture japonaise contemporaine. La musique japonaise n'est donc en aucun cas l'une des musiques de l'Orient. Elle est la somme des musiques de l'Orient, elle est la somme des musiques du monde.

我が日本は地理的に見て東亜の一部であるとも言へる。又た日本音楽は歴史的 に見て東亜音楽の一部であるとも言へる。然しその事を表面的に考へてはなら ぬ。[...] 何故かといふに、日本はアジアの中心に位する。[...] 従つて太古より今 日に至るまで此の凡ての文化交通路は我が日本に集まり、従つてその文化は日 本に集まつて集積され、綜合され、消化され、日本人の独創性によつて建設さ れ、斯くして独自なる日本文化が作り上げられたのであつて、今日は欧米の文 化も亦た直ちに日本に入つて現代日本の文化を作りつつある。従つて日本音楽 は決して東亜音楽の一系ではなくて、一面に於ては東亜音楽の集大成であり、 一面に於ては世界音楽の集成である。

Le contenu de cette "musique orientale" n'est pas sans poser un problème de cohérence. On peut faire le lien ici avec la «Sphère de coprospérité de la Grande Asie orientale », cette tentative initiée par le gouvernement japonais en 1940 pour asseoir son leadership économique sur les pays asiatiques qu'il domine. « Musique de la Grande Asie orientale » et "Sphère de coprospérité de la Grande Asie orientale » sont l'une et l'autre des produits fantasmés du colonialisme japonais, et ne correspondent à aucune réalité concrète. Dans ce contexte, lorsque Tanabe est amené à donner sens à ce concept, c'est au gagaku qu'il attribue le rôle de «somme des musiques du monde » et de " musique de la Grande Asie orientale $»^{92}$ :

Seul le gagaku peut être reconnu aujourd'hui comme le leader de la culture des pays de la Grande Asie orientale. Importé de Chine, d'Inde et du Pacifique sud, raffiné et développé au Japon durant un millénaire, le gagaku est respecté comme musique de la Grande Asie orientale par tous les pays [...]. Je suis convaincu que dès lors que le gagaku sera exporté dans les pays de la Grande Asie orientale il jouera le rôle de principe unificateur de la musique de la Grande Asie orientale.

たメ゙一つ今日直ちに持つて行つて彼等が大東亜文化の指導者として眞に尊敬し

得るものは雅楽があるのみである。雅楽及び舞楽は元来唐や印度や南洋方面か ら輸入されて、而も千年の年月を経て我が国で精鍊発達したものであるから、 今日そのま 入大東亜音楽として萬邦斎しく仰き見るものではある $[. .$.$] 。但し一$ 旦これが大東亜諸国へ持ち出された暁には、恐らく大東亜音楽の中心はこれに よつて統一されるに至るであらうと信じてみる。 


\section{Le gagaku comme patrimoine national et universel}

50 Cette vision du gagaku est évidemment la plus idéalisée de toutes celles qui ont vu le jour au cours de son histoire. On aurait pu s'attendre à ce qu'elle ne résiste pas au choc de la défaite de 1945, pourtant on en trouve encore la trace, sous une forme différente, dans les discours d'après-guerre. Le gagaku d'avant-guerre, identifié à la «musique de la Grande Asie orientale», est alors revendiqué comme "bien culturel immatériel important $»$ du Japon ${ }^{93}$ :

Parmi les musiques classiques de notre pays, c'est le gagaku qui est respecté mondialement en tant qu'art universel.

我国の古典楽の中において、そのまま国際的の性質を帯びた芸術として世界の

尊敬を受けて居るものは雅楽である。

51 En somme, le gagaku expérimente alors une seconde façon d'être universel: d'art pouvant unifier, par un passé formant un socle commun, plusieurs cultures d'Asie, il prend désormais le statut de patrimoine mondial reconnaissable par sa singularité et son ancienneté.

En 1955, Tanabe est l'un des dix-neuf membres du jury statuant sur les biens culturels (bunkazai senmon shingi iin 文化財専門審議委員) de la section des Arts du spectacle du Comité pour la protection des biens culturels du ministère de l'Éducation. Dans le commentaire anonyme qui accompagne la décision de distinguer le gagaku, on reconnaît parfaitement sa vision de l'histoire du gagaku en trois stades (musique ancienne, importée, japonisée) et sa foi dans le gagaku comme musique déjà présente à l'origine du Japon et donc du monde ${ }^{94}$ :

[Le gagaku] est le spectacle le plus ancien du monde : il est constitué de la musique ancienne de notre pays et des musiques importées du continent asiatique qui ont fusionné, et qui ont été ensuite japonisées vers l'époque de Heian. Il a disparu à l'étranger et subsiste seulement dans notre pays. Il est à la source de tous les genres de musique pratiqués au Japon au cours de son histoire.

[...] Seul le département de Gagaku de l'Agence impériale conserve dans son authenticité cette musique pour les générations futures et peut l'exécuter de façon artistique.

わが国古来の音楽と、アジヤ大陸の諸国から伝来した音楽とが、渾然融合し、 わが国風に大体平安朝頃に改整せら扎た世界最古の芸能で、外国では滅亡し、

ひとりわが国にのみ层えられており、各種邦楽の源流をなしている。

[...]正統に质え、芸術的に演じ得るのは宮内庁楽部である。 


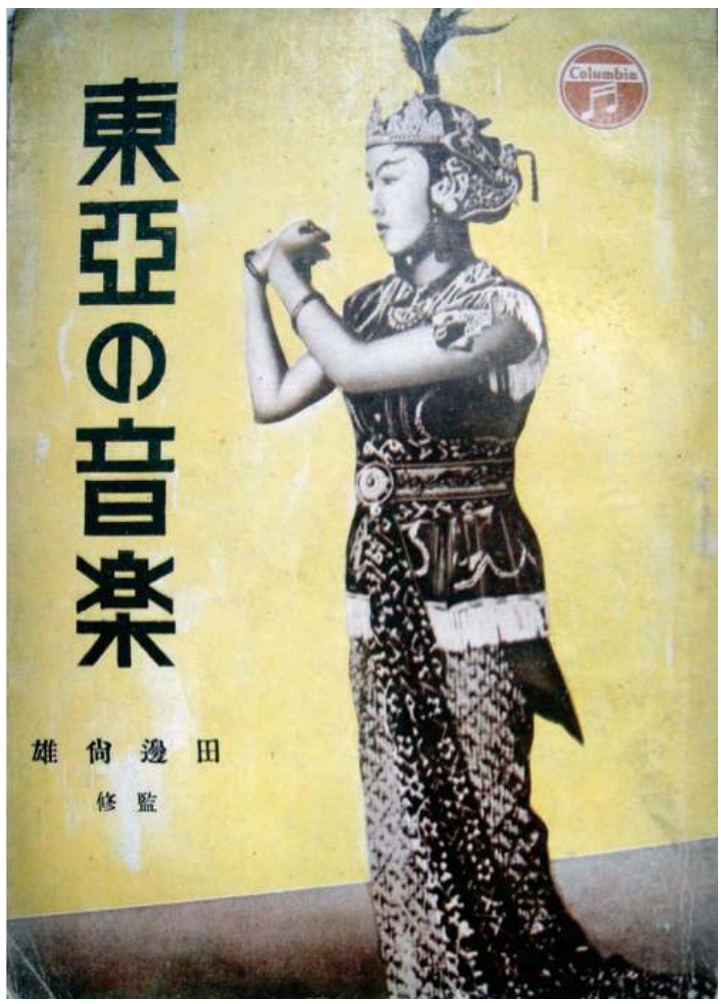

Appendice de la collection des disques Musique de l'Asie orientale Tanabe Hisao, Tōa no ongaku 東亜の 音楽 (Musique de l'Asie orientale), Tōa no ongaku, Tōkyō, Columbia-Nipponophone コロムビア・ニッ ポノフォン, 1941

\section{Conclusion}

Dans cet article, nous avons essayé de suivre pas à pas de quelle façon, à chaque grande étape de l'histoire moderne du Japon, le gagaku a été mobilisé en tant que symbole de la culture nationale. Nous avons vu comment, à l'ère Meiji, en un temps où le Japon devait s'ériger en État-nation, le gagaku a été redéfini à la fois comme musique de cour et musique du peuple japonais, à l'initiative de la section de Gagaku de la cour impériale. Puis, au tournant du siècle, sous l'influence de la musicologie occidentale contemporaine et de l'un de ses introducteurs au Japon, Tanabe Hisao, comment s'est répandue une nouvelle vision du gagaku, distinguant trois registres (musique autochtone ancienne, musique importée, musique japonisée) permettant de faire de cet art la musique à la fois la plus ancienne et la plus évoluée du Japon. Cette perception, alliant de façon très adroite la logique impériale de la nécessité d'une validité par l'histoire et idéologie moderniste et scientifique caractéristique des nations industrialisées, est dominante dans les années 1910 à 1920, à l'époque de la démocratie de Taishō. Quelques années plus tard, et dans un Japon conquérant, mais toujours sous l'influence de Tanabe, le gagaku se voit accorder, en évoquant un patrimoine commun qui connaîtrait sa forme la plus évoluée au Japon, le statut de musique de la Grande Asie orientale, instrument de l'unification des divers territoires sous domination japonaise. Nous avons expliqué enfin en quoi la nécessaire inscription du gagaku au patrimoine culturel immatériel du Japon, après-guerre, mais dans la continuité de la précédente définition, se situait dans la construction d'une identité culturelle nationale 
oscillant entre les deux pôles que sont le nationalisme et l'universalisme. Le gagaku « immuable» et «authentique » se trouve désormais éternellement conservé dans la liste du patrimoine japonais pour contribuer à former la mémoire collective.

En général, on a tendance à voir une rupture de pensée entre l'avant-guerre et l'aprèsguerre. En réalité, après la défaite, le Japon a commencé à avancer dans la voie d'un «nationalisme culturel » qui a succédé au nationalisme d'avant-guerre et ce, au nom même de la démocratie. La raison en est que durant la période d'occupation par l'armée américaine (1945-1953), le Japon a dû chercher à renaître de ses cendres en s'appuyant sur des principes que résument bien les slogans «minzoku no fukkō 民族の復興》 (Renaissance de la nation) et «bunka kokka 文化国家》 (Un État fort par sa culture) ${ }^{95}$. C'est donc ce contexte historique qui est à l'origine, à partir de 1950, du processus ayant conduit à la nomination du gagaku comme bien culturel national par le ministère de l'Éducation, en 1955. De même que d'autres intellectuels qui formaient l'élite à l'ère Taishō sont devenus des forces conservatrices après-guerre ${ }^{96}$, Tanabe a servi à la reconstruction de la culture japonaise impériale d'après-guerre, et de fait, à l'établissement de ce «nationalisme culturel». Et ce sont ses élèves, notamment Kishibe Shigeo et Kikkawa Eishi 吉川英史 (1909-2006), qui ont assuré le développement de la musique japonaise après-guerre. Certes, on peut dire qu'ils ont lutté pour "sauvegarder" la musique japonaise en cherchant à affirmer son identité culturelle contre le risque d'abandon des traditions que connaissait la nouvelle société sous occupation américaine. Mais dans le même temps, la patrimonialisation du gagaku permet au Japon d'oublier l'histoire de la colonisation musicale au profit d'une relecture plus positive, décrivant le gagaku comme vestige culturel du continent asiatique. L'histoire de la musique japonaise moderne reflète ainsi le processus par lequel le Japon a cherché à affirmer son identité culturelle depuis la fin du XIX siècle. 


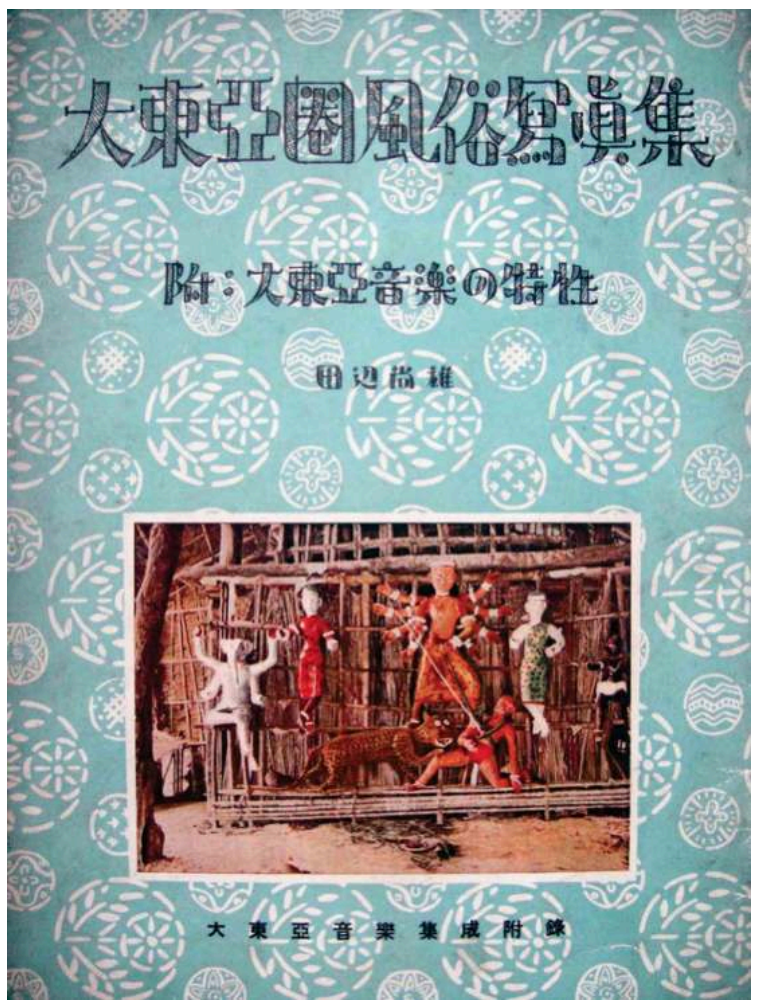

Appendice de la collection de la Musique de la Grande Asie orientale. Tanabe Hisao, Daitōa ken fūzoku shashin shū. Fu : daitōa ongaku no tokusei 大東亜圏風俗写真集 : 附 : 大東亜音楽の特性 (Collection de photos du folklore de la sphère de la Grande Asie orientale. Annexe : Caractéristiques de la Grande Asie orientale), Daitōa ongaku shūsei 大東亜音楽集成 (Collection de la musique de la Grande Asie orientale), Tōkyō, Japan Victor Records 日本ビクターレコード, 1942.

\section{BIBLIOGRAPHIE}

\section{Euvres de Tanabe Hisao}

(Liste partielle. Sauf mention contraire le lieu d'édition est Tōkyō)

Onkyō to ongaku 音響と音楽 (l'Acoustique et la musique), Kōdōkan 弘道館, 1908.

Seiyō ongaku kōwa 西洋音楽講話 (Conférence sur la musique européenne), Iwanami shoten 岩波 書店, 1915 .

Saikin kagakujō yori mitaru ongaku no genri 最近科学上より見たる音楽の原理 (Principes musicaux considérés du point de vue des sciences modernes), Uchida rōkaku ho 内田老鶴圃, 1916.

Nihon ongaku kōwa 日本音楽講話 (Conférence sur la musique japonaise), Iwanami shoten 岩波書 店, 1919 .

Gagaku Tsūkai 雅楽通解 (Interprétation du gagaku), Kokyoku hozon kai 古曲保存会, 1921. 
Chōsen riōke no kogakubu : waga kyūchū no bugaku tono kankei 朝鮮李王家の古楽舞 : 我が宮中の舞 楽との関係 (l'Ancienne musique et danse de la cour de la dynastie Rī en Corée : par rapport au bugaku de la cour de notre pays), Keimei kai daigokai kōen-shū 啓明会第五回講演集, Keimei-kai 啓 明会, 1921.

Nihon ongaku no kenkyū 日本音楽の研究 (Études sur la musique japonaise), Kyōbunsha 京文社, 1926.

Tōyō ongaku shi 東洋音楽史 (Histoire de la musique orientale), Yūzan kaku 雄山閣, 1930.

Tōyō ongaku no inshō 東洋音楽の印象 (Impression de la musique orientale), Jinbun shoin 人文書 院, 1941.

Daitōa to ongaku 大東亜と音楽 (la Grande Asie orientale et la Musique), Monbushō Kyōgaku kyoku 文部省教学局, 1942.

Daitōa no ongaku 大東亜の音楽 (la Musique de la Grande Asie orientale), Kyōwa shobō協和書房, 1943, (rééd. Ōzorasha大空社, 2003).

《Koten ongaku no bunka-zai toshite no kachi 古典音楽の文化財としての価値 » (la Valeur de la musique classique comme biens culturels), Bunkazai geppō 文化財月報 (Rapport mensuel des biens culturels), Bunkazai hogo iinkai 文化財保護委員会 (Comité pour la protection des biens culturels), nº 1, décembre 1951.

Nanyō Taïwan Okinawa ongaku chōsa kikō 南洋 ·台湾・沖縄音楽調査紀行 (Voyage de recherches musicales au Pacifique sud, à Taïwan et à Okinawa), Ongaku no tomo sha 音楽の友社, 1968.

Chūgoku chōsen ongaku chōsa kikō 中国 · 朝鮮音楽調査紀行 (Voyage de recherches musicales en Chine et en Corée), Ongaku no tomo sha 音楽の友社, 1970.

Tanabe Hisao jijoden 田辺尚雄自叙层 (Autobiographie de Tanabe Hisao), Hōgaku sha 邦楽社, 1981. Zoku Tanabe Hisao jijoden 続田辺尚雄自叙伝 (Suites de l'autobiographie de Tanabe Hisao), Hōgaku sha 邦楽社, 1981

\section{Références discographiques de Tanabe}

Heian-chō ongaku rekōdo 平安朝音楽レコード (les Disques de musique de la cour de Heian), 20 disques, Heian chō Record 平安朝レコード, Imperial Record インペリアルレコード, 1921.

Tōa no ongaku 東亜の音楽 (Musique de l'Asie orientale), 10 disques, S6001A-S6010B, ColumbiaNipponophoneコロムビア・ニッポノフォン, 1941 (rééd. Columbia music entertainment, COCG-14342, 1997).

(Avec la Société Orientale de Musique) : Daitōa ongaku shūsei 大東亜音楽集成 (Collection de la musique de la Grande Asie orientale), 36 disques, Japan Victor Records 日本ビクターレコード, 1942.

Tanabe Hisao, Kurosawa Takatomo 黒澤隆朝 et Masu Genjirō 桝源次郎, Nanpō no ongaku 南方の 音楽 (Musique du sud [de l'Asie]), 6 disques, S6016-S6021, Columbia-Nipponophone コロムビ ア・ニッポノフォン, 1942 .

\section{Études complémentaires}

BoILÈs Charles et NATTIEZ Jean-Jacques, « Petite histoire critique de l'ethnomusicologie », Musique en jeu, $\mathrm{n}^{\circ} 28,1977$, p. 26-53.

FUJII Kōki 藤井浩基, Ongaku ni miru shokuminchi ki Chōsen to nihon no kankei shi : 1920 -30 nendai no nihonjin no katsudōo chūshin ni 音楽にみる植民地期朝鮮と日本の関係史 : 1920-30年代の日本人 による活動を中心に (Histoire du rapport entre la Corée sous l'occupation japonaise et le Japon 
du point de vue de la musique : sur les pratiques des Japonais des années 1920 et 1930), Thèse en arts et cultures 芸術文化学, Université des arts d'Ōsaka, 2008.

OSA Shizue 長志珠絵, «Kokka to kokugaku no isō 国歌と国楽の位相 » (Aspects de l'hymne national et de la musique nationale), dans Nishikawa Nagao 西川長夫 et Matsumiya Shūji 松宮秀 治 (dir.), Bakumatsu meiji ki no kokumin kokka keisei to bunka henyō 幕末 - 明治期の国民国家形成 と文化变容 (Formation de l'État-nation et transformations culturelles à la fin de l'époque d'Edo et à l'ère Meiji), Shin.yōsha 新曜社, 1995, p. 455-486.

TERAUCHI Naoko 寺内直子, Gagaku no « kindai » to « gendai » : keishō, fukyū; sōzō no kiseki 雅楽の<近 代>と<現代> : 継承・普及・創造の軌跡 (le Gagaku à l'« époque moderne » et à l'« époque contemporaine » : le parcours de la transmission, de la diffusion et de la création), Iwanami shoten 岩波書店, 2010.

UEMURA Yukio 植村幸生, « Tanabe Hisao to tōyō ongaku no gainen » 田辺尚雄と「東洋音楽」の 概念 (Tanabe Hisao et l'idée de la 'musique orientale'), dans Asakura Yūko 浅倉有子 et Jōetsu kyōiku daigaku higashi ajia kenkyū kai 上越教育大学東アジア研究会 (éd.), Rekishi hyōshō to shiteno higashi ajia 歴史表象としての東アジア, Seibundō 清文堂, Ōsaka, 2002, p. 225-239.

UEMURA Yukio 植村幸生, « Nihonjin ni yoru Taiwan shōsū minzoku no kenkyū : Tanabe, Kurosawa, Koizumi no gyōseki o chūshin ni »日本人による台湾少数民族音楽の研究: 田辺・黒 沢・小泉の業績を中心に (Recherches sur la musique des minorités ethniques taïwanaises par les Japonais : sur les travaux de Tanabe, de Kurosawa et de Koizumi), Jōetsu kyōiku daigaku kiyō 上 越教育大学研究紀要, $n^{\circ} 22-2,2003$, p. 301-312.

WATANABE Hiroshi 渡讱裕, Nihon bunka modan rapusodī 日本文化モダンラプソディー (Culture japonaise, rhapsodie moderne), Shunjūsha 春秋社, 2004.

YAMAZUMI Masami 山住正巳, « Gagaku to ten'nō sei : tokuni shōka kyōiku seiritsu ki o chūshin ni » 雅楽と天皇制 : とくに唱歌教育成立期を中心に (Gagaku et régime impérial : la période de la formation de l'éducation du chant à l'école), Rekishi hyōron 尓史評論, $\mathrm{n}^{\circ} 602$, juin 2000, p. 2-13.

\section{NOTES}

1. Kanpō 官報 (Journal officiel), 12 mai 1955. Le Japon est le premier pays au monde à avoir adopté la désignation de «bien culturel immatériel » (mukei bunkazai 無形文化財) ; Voir Bruno NETTL, The Western Impact on World Music: Change, Adaptation, and Survival, New York, Schirmer books, 1985. La Convention pour la sauvegarde du patrimoine culturel immatériel de l'UNESCO, inspirée par le japonais Matsuura Kōichirō 松浦晃一郎, directeur général de l'UNESCO, a été adoptée en octobre 2003 en prenant comme modèle le système patrimonial immatériel du Japon ; Mariannick JADÉ, Patrimoine immatériel : Perspectives d'interprétation du concept de patrimoine, Paris, L'Harmattan, 2006, p. 85-86.

2. Sur l'histoire de la création du patrimoine et des canons du Japon moderne dans le domaine des beaux-arts et de la littérature, voir SATō Dōshin 佐藤道信, «Nihon bijutsu » tanjō : Kindai Nihon no «kotoba» to senryaku〈日本美術〉誕生：近代日本の「ことば」と戦略 (la Naissance des «beaux-arts japonais » : les « mots » et la stratégie du Japon moderne), Kōdansha sensho mechie 講談社選書メチエ, Tōkyō, Kōdansha 講談社, 1996 ; Christophe MARQUET, «Conscience patrimoniale et écriture de l'histoire de l'art national », dans Claude HAMON et Jean-Jacques TSCHUDIN (dir.), la Nation en marche, Arles, Éditions Philippe Picquier, 1999, p.143-162; Id., «le Japon moderne face à son patrimoine artistique ", Cipango, numéro hors-série "Mutations de la conscience dans le Japon moderne », printemps 2002, p. 243-304. Sur la littérature japonaise, voir HARUo Shirane ハルオ・シラネ et SUZUKI Tomi 鈴木登美 (éd.), Sōzō sareta koten: kanon keisei, 
kokumin kokka, nihon bungaku 創造された古典 : カノン形成・国民国家・日本文学 (la Littérature classique inventée : formation du canon, État-Nation, littérature japonaise), Tōkyō, Shin.yōsha 新曜社, 1999 ; Emmanuel LOZERAND, Littérature et génie national : naissance d'une histoire littéraire dans le Japon du $\mathrm{XIX}^{\mathrm{e}}$ siècle, Paris, Les Belles Lettres, 2005.

3. 正統に伝え、芸術的に演じ得るのは宮内庁楽部である; Bunkazai hogo iinkai 文化財保護委 員会, “Gagaku», Liste des biens culturels immatériels, Kikan bunkazai 季刊文化財 (Rapport trimestriel des biens culturels), vol. 3, 1955, p. 41.

4. Voir par exemple l'entrée «Gagaku » 雅楽 du dictionnaire Kōjien 広辞苑, $6^{\mathrm{e}}$ édition, Tōkyō, Iwanami Shoten 岩波書店, 2008, p. 484.

5. Cf. par exemple Nihon ongaku daijiten 日本音楽大事典 (Grand dictionnaire de la musique japonaise), Tōkyō, Heibonsha 平凡社, 1989; Gagaku daijiten 雅楽大事典 (Grand dictionnaire du gagaku), Tōkyō, Ongaku no tomo sha 音楽の友社, 1989.

6. TANABE Hisao, KIKKAWA Eishi 吉川英士 et HIRAIDE Hisao 平出久雄, «Nihon no gagaku » 日本の雅 楽 (le Gagaku du Japon), Ongaku jiten 音楽事典 (Dictionnaire de la musique), vol. 2, Tōkyō, Heibonsha, 1955, p. 206-216.

7. François PICARD, la Musique chinoise, Paris, Minerve, 1991, p. 46 et p. 80.

8. Entretiens de Confucius (Lun yu 論語), chapitre 17, paragraphe 18.

9. Ibid., chapitre 13, paragraphe 3. Voir Véronique ALEXANDRE-JOURNEAU, «Avant-propos », dans Yueji 樂記 : le Livre de musique de l'Antiquité chinoise, configuré et traduit par Véronique AlexandreJourneau, Paris, You-Feng, 2008, p. XIII.

10. Entretiens de Confucius, chapitre 17, paragraphe 18.

11. Sur l'histoire du gagaku ancien, voir OGI Mitsuo 荻美津夫, Nihon kodai ongakushi ron 日本古代 音楽史論 (Études sur l'histoire de l'ancienne musique du Japon), Tōkyō, Yoshikawa kōbunkan 吉 川弘文館, 1977, p. 27-61.

12. Shoku nihon-gi 続日本紀 (Suites des Chroniques du Japon), à l'article du jour aîné de la terre et du chien, septième mois de la première année de l'ère Taihō (701).

13. OGI Mitsuo, op. cit., p. 16.

14. Ibid., p. 76-77. Ces registres de la musique se trouvent dans un document officiel du ministère des Affaires suprêmes daté du $9^{\mathrm{e}}$ mois de l'année 848 .

15. Francine HÉRAIL, La Cour et l'Administration du Japon à l'époque de Heian, Genève, Droz, 2006, p. 27 et p. 663-666.

16. Registre au sein duquel on compte aussi la «musique de Champa » (rin.yū-gaku 林邑楽), du nom du royaume situé dans la partie centrale du Viêtnam, ainsi que les pièces composées par les Japonais sur le modèle de la « musique des Tang».

17. Qui, outre la «musique de Koguryŏ » à proprement parler, comprend la " musique de Silla », la « musique de Paekche » et la «musique de Balhae» (bokkai-gaku 渤海楽), royaume fondé après la chute de Koguryŏ, soit l'ensemble des musiques originaires de la péninsule coréenne.

18. Francine HÉRAIL, op. cit., p. 664.

19. OGI Mitsuo 荻美津夫, Heian-chō ongaku seidoshi 平安朝音楽制度史 (Histoire des institutions musicales à l'époque de Heian), Tōkyō, Yoshikawa kōbunkan, 1994, p. 24-57 et p. 137-228.

20. Ibid., p. 23.

21. Id., Nihon kodai ongakushi ron, op. cit., p. 17-21.

22. NISHIYAMA Matsunosuke 西山松之助, Iemoto no kenkyū 家元の研究 (Études sur le modèle d'organisation familiale des arts), Tōkyō, Yoshikawa kōbunkan, 1989, p. 161-168.

23. Sur les études sur le gagaku à l'époque d'Edo, voir ōTsUKI Kunio 大築邦雄, « Kinsei no gagaku kenkyū» 近世の雅楽研究 (les Études sur le gagaku à l'époque d'Edo), Ongaku-gaku 音楽学 (Musicologie), 10-3, 1964.

24. Sur l'institutionnalisation du gagaku à l'époque d'Edo, voir OGAWA Tomoko 小川朝子, « Kinsei no bakufu girei to sanpō gakuso » 近世の幕府儀礼と三方楽所 (les Cérémonies du shôgunat et 
trois organes de la « Musique » à l'époque d'Edo), dans IMATANI Akira 今谷明 et TAKANo Toshihiko 高埜利彦 (dir.), Chūkinsei no kokka to shūkyō 中近世の宗教と国家 (la Religion et l'État prémoderne), Tōkyō, Iwata shoin 岩田書院, 1998, p. 407-446; Id., « Gakunin »楽人 (les Musiciens de gagaku), dans чокотА Fuyuhiko 横田冬彦 (dir.), Geinō bunka no sekai 芸能文化の世界 (le Monde de la culture de l'art du spectacle), Tōkyō, Yoshikawa kōbunkan, 2000, p. 19-53.

25. Sur la reconstitution du gagaku de l'époque d'Edo, voir HIRAIDE Hisao 平出久雄, «Edo jidai no kyūtei ongaku saikō oboegaki » 江戸時代の宮廷音楽再興覚え書 (Essai sur la reconstitution de la musique de cour à l'époque d'Edo), Gakudō楽道 (la Voie des arts), vol. 212 à 215, juin à septembre 1959; TSUKAHARA Yasuko 塚原康子, Meiji kokka to gagaku 明治国家と雅楽 (l'État de Meiji et le gagaku), Tōkyō, Yūshisha 有志舎, 2009, p. 15-41.

26. MATSUDAIRA Sadanobu, Zokugaku mondō 俗楽問答 (Dialogue sur la musique populaire; 1829), dans Rakūo-kō isho 楽翁公遺書 (Recueil posthume des textes de Rakuō), EMA Seihatsu 江間政発 (éd.), volume 2, Tōkyō, Yao shoten 八尾書店, 1893, p. 13-34.

27. TSUKAHARA, op. cit., p. 47-51.

28. Ibid., p. 42-71. Sur l'invention des «traditions » de la culture impériale, voir TAKAGI Hiroshi 高 木博志, Kindai tennōsei no bunkashiteki kenkyū: Tennō shūnin girei, nenchū gyōji, bunkazai 近代天皇 制の文化史的研究: 天皇就任儀礼·年中行事 - 文化財 (Recherches sur les aspects culturels du système impérial à l'époque moderne : Rites d'intronisation de l'empereur, rites saisonniers et patrimoine culturel), Tōkyō, Azekura shobō 校倉書房, 1997; François Macé, «le Shintō désenchanteur", Cipango, numéro hors-série "Mutation de la conscience dans le Japon Moderne ", printemps 2002, p. 7-70.

29. TSUKAHARA, op. cit., p. 195-196.

30. La présence de l'empereur Meiji lors d'une représentation est en effet une condition essentielle de l'affirmation du statut d'un art. Cela adviendra en 1874 pour le nō, en 1887 pour le kabuki, par exemple.

31. Ongaku ryakuge 音楽略解 (Interprétation brève de la musique), 1878. Cet ouvrage est consultable au Département des archives et des mausolées de l'Agence impériale (Kunai-chō shoryō-bu 宮内庁書陵部).

32. TSUKAHARA, op. cit., p. 35.

33. L'Institut, établi en 1879, devient l'École nationale de musique de Tōkyō (Tōkyō ongaku gakkō 東京音楽学校) en 1889, elle-même à l'origine de la Faculté de musique de l'Université des arts de Tōkyō (Tōkyō geijutsu daigaku ongaku gakubu 東京藝術大学音楽学部), créée en 1946.

34. Anne-Marie THIESSE, la Création des identités nationales : Europe $\mathrm{xVIII}^{\mathrm{e}}-\mathrm{xx}$ siècle, Paris, Éditions du Seuil, 1999, ici p.139-140. Au Japon, le concept de "musique nationale» est utilisé pour la première fois par KANDA Kōhei 神田孝平 (1830-1898) dans son article « Kokugaku o shinkō subeki no setsu»国楽习振興スヘキノ說 (De la nécessité de développer une musique nationale), Meiroku zasshi 明六杂隹誌, $\mathrm{n}^{\circ} 18$, octobre 1874, p. 7-8.

35. Voir Benedict ANDERSON, l'Imaginaire national : réflexions sur l'origine et l'essor du nationalisme, Paris, La Découverte (La découverte Poche), 2002, p. 145-168 (Imagined Communities: Reflections on the Origin and Spread of Nationalism, Verso, London, New York, 1983). Voir aussi le travail de Jane F. FULCHER, French Cultural Politics \& Music: From the Dreyfus Affair to the First World, Oxford, New York, Oxford University Press, 1999.

36. Voir supra.

37. OKUNAKA Yasuto 奥中康人, Kokka to Ongaku 国家と音楽 (L’État et la musique), Tōkyō, Shūnjūsha 春秋社, 2008, p. 48-59.

38. Dajōkan nisshi 太政官日誌 (Journal officiel du ministère des Affaires suprêmes), $\mathrm{n}^{\circ} 75$, $5^{\mathrm{e}}$ année de Meiji (1872) ; reéd. Tōkyō-dō shuppan 東京堂出版, 1990, p. 188.

39. TSUKAHARA, op. cit., p. 42-71.

40. Ibid., p. 79-83. 
41. Gagaku-roku 雅楽録 (Registre officiel du gagaku), $\mathrm{n}^{\circ} 10,11^{\mathrm{e}}$ année de Meiji (1878). Ces registres sont consultables au département des Archives et des Mausolées de l'Agence impériale. Sur le gagaku à l'Exposition universelle de Paris en 1878, voir TSUKAHARA, op. cit., p. 144-148; Inoue Satsuki 井上さつき, Ongaku o tenji suru: Pari banpaku 音楽を展示する: パリ万博 1855-1900 (Exposer la musique: Exposition universelle de Paris 1855-1900), Tōkyō, Hōsei daigaku shuppankyoku 法政大学出版局, 2009, p. 196-198.

42. Nihon gagaku gaiben 日本雅楽概弁 (Propos sur le gagaku du Japon), 1878. Rouleaux manuscrits en neuf volumes consultables au département des Archives et des Mausolées de l'Agence impériale.

43. Gagaku-roku, $\mathrm{n}^{\circ} 22,11^{\mathrm{e}}$ année de Meiji (1878).

44. Sondra Wieland HowE, "Music Teaching in the Boston Public Schools, 1864-1879", Journal of Research in Music Education, Vol. 40, no. 4, Winter 1992, p. 316 et p. 326.

45. MEGATA Tanetarō, « Waga kōgaku ni shōka no ka o okosubeki shikata ni tsuite watakushi no mikomi » 我公学二唱歌ノ課习與スベキ仕方ニツキ私ノ見込 (Mes prévisions sur la façon de fonder la classe musicale dans l'école communale de notre pays), 20 avril 1878, repris dans Tōkyō geijutsu daigaku hyakunen shi henshū iinkai 東京芸術大学百年史編集委員会 (Comité d'édition des cent ans d'histoire de l'Université des arts de Tōkyō), Tōkyō geijutsu daigaku hyakunen shi: Tōkyō ongaku gakkō hen 東京芸術大学百年史: 東京音楽学校篇 (Cent ans d'histoire de l'Université des arts de Tōkyō: Tome du Conservatoire de musique), vol. 1, Tōkyō, Ongaku no tomo sha, 1987, p. 15-17.

46. Voir OKUNAKA, op. cit., p. 149-151.

47. Ongaku torishirabe seiseki shinpō sho 音楽取調成績申報書 (Rapport d'activité de l'Institut de recherches sur la musique), Institut de recherches sur la musique, 1884, p. 67-79 et p. 81-99.

48. 《Kokugaku seitei to gagaku kyōkai» 国楽制定と雅楽協会 (la Fondation de la musique nationale et l'Association du gagaku), Teikoku bungaku 帝国文学 (Littérature impériale), 1-3, mars 1895, rubrique « Faits divers » (zappō 杂佳報).

49. Voir Philip von bohlman, "Landscape-Region-Nation-Reich: German Folk Song in the Nexus of National Identity", C. APPLEGATE \& P. POTTER (ed.), Music \& German National Identity, Chicago and London, University of Chicago Press, 2002.

50. Dans son article intitulé «Girisha no min.yō" 希臘の民謡 (Chants populaires de Grèce), Shigarami zōshiしらがみ草紙, vol. 35, août 1892, p. 4-5.

51. SHINADA Yoshikazu 品田悦一, Man.yōshū no hatsumei: Kokumin kokka to bunka sōchi to shite no koten 万葉集の発明：国民国家と文化装置としての古典 (l'Invention du Man.yō-shū: l'Étatnation et la littérature classique comme dispositif culturel), Tōkyō, Shin.yōsha, 2001, p. 191-195.

52. Il y travaille sous la direction de Haga Yaichi 芳賀矢一 (1867-1927) qui a étudié la philologie en Allemagne. Sur le département de Littérature nationale à l'Université impériale de Tōkyō et le rôle de Haga, voir SHINADA Yoshikazu, op. cit., p. 187-196 et p. 210-218; HANAMORI Shigeyuki 花森重 行, «Kokubungaku kenkyū shi ni tsuite no ichikōsatsu : 1890 nendai no Haga Yaichi o megutte » 国文学研究史についての一考察：1890年代の芳賀矢一をめぐって (Une analyse sur l'histoire des recherches sur la littérature nationale : autour de Haga Yaichi des années 1890), Ōsaka daigaku nihon gakuhō 大阪大学日本学報, vol. 21, mars 2002, p. 71-85. Voir aussi le travail d'Emmanuel LOZERAND, op. cit.

53. SHIDA Yoshihide, «Nihon min.yō gairon»日本民謡概論 (Principes des chants folkloriques japonais), Teikoku bungaku 帝国文学 (Littérature de l'empire), 12-2, 12-3, 12-5 et 12-9, 1906.

54. Le sens littéral du mot saibara 催馬楽 est «air » ( $r a$ 楽) pour « encourager » (sai 催) 《les chevaux » (ba 馬).

55. Kokushi daijiten 国史大辞典, Tōkyō, Yoshikawa kōbunkan, 1908, p. 543. Les pièces vocales se répartissent dans les registres suivants : kagura-uta 神楽歌; kume-uta 久米歌, chants du clan Kume, donnés, au moment où Shiba rédige son article, lors de la commémoration de l'avènement 
au trône de l'empereur Jinmu (kigensetsu 紀元節) ; azuma-asobi 東遊, chantés à l'anniversaire de la mort de l'empereur Jinmu et lors des deux équinoxes ; ta-uta 田歌, chants pour le repiquage du riz, mobilisés lors de la célébration des Grandes Prémices (daijo-e 大嘗会) ; yamato-uta 大和歌, chants de la région du Yamato, entonnés aussi lors de la célébration des Grandes Prémices; utagaki 歌坦, chants entre les femmes et les hommes, dont on ne trouve plus d'évocation après 770 ; saibara 催馬楽; rōei 朗詠; fuzoku 風俗, chants populaires des diverses provinces, eux aussi utilisés lors la célébration des Grandes Prémices ; kuzubito-uta 国栖人歌, « chants du peuple de Kuzu » qui ne sont mentionnés que dans les anciens textes tels que le Kojiki ou le Nihonshoki.

56. TōGI Tetteki 東儀鉄笛, Ongaku nyūmon 音楽入門 (Initiation à la musique), Tōkyō, Waseda daigaku shuppan bu 早稲田大学出版部, 1910.

57. TANABE Hisao, Tanabe Hisao jijoden 田辺尚雄自叙伝 (Autobiographie de Tanabe Hisao), Tōkyō, Hōgakusha 邦楽社, 1981, p. 158-159 et p. 235-236.

58. Ibid., p. 150.

59. Ibid., p. 215. Abordant pour la première fois la musique du point de vue «objectif » des sciences, cet ouvrage a fortement inspiré la musicologie en Europe dans la deuxième moitié du $\mathrm{XIX}^{\mathrm{e}}$ siècle. Hermann von HELMHOLTZ, Die Lehre von den Tonempfindungen als physiologische Grundlage für die Theorie der Musik, Braunschweig: Friedrich Vieweg und Sohn, 1863. Traduction française par George Guéroult (1868), Paris, rééd. Éditions Jacques Gabay, 1990. La musicologie (»Musikwissenschaft«) est présentée pour la première fois comme discipline prenant pour modèle les sciences naturelles de Newton dans un article intitulé "Über Musik als Musikwissenschaft« (Sur la musique comme musicologie) de l'Allgemeine musikalische Zeitung à Leipzig en mars 1827. Cette première approche sera systématisée au début de $\mathrm{xx}^{\mathrm{e}}$ siècle par l'élève de Helmholtz Carl Stumpf (1848-1936), le musicologue de l'Université de Vienne Guido Adler (1855-1941), et Hugo Riemann (1849-1918). Sur la naissance de la musicologie en Europe, voir John HAINES, «Généalogies musicologiques aux origines d'une science de la musique vers 1900 », Acta musicologica, 73, $\mathrm{n}^{\circ} 1,2001$, p. 21-44.

60. Sur la conception qu'avait Tanaka de la musique nationale, voir HIRATSUKA Tomoko 平塚智子, « 'Hattatsu' suru nihon ongaku : Tanaka Shōhei no risō to riron o megutte»「発垟」する日本音 楽: 田中正平の理想と実践をめぐって (《Développement» de la musique japonaise : à propos des idées et les théories de Tanaka Shōhei), Hikaku bungaku kenkyū 比較文学研究 (Recherches de littérature comparée), $\mathrm{n}^{\circ}$ 71, 1998, p. 109-128.

61. KONAKAMURA Kiyonori 小中村清矩, Kabu-ongaku ryakushi 歌舞音楽略史 (Histoire sommaire de la musique, du chant et de la danse), Yoshikawa Hanshichi 吉川半七, Tōkyō, 1888, rééd. Tōkyō, Iwanami bunko 岩波文庫, Iwanami shoten 岩波書店, (1928), 2000.

62. Souligné par TANABE, Nihon ongaku kōwa, Tōkyō, Iwanami shoten, 1919, p. 69.

63. Souligné par TANABE, ibid., p. 341.

64. TANABE, Gagaku tsūkai 雅楽通解 (Interprétation du gagaku), Tōkyō, Kokyoku hozon kai 古曲保 存会, 1921 .

65. Sur l'histoire de la naissance du phonographe, voir Philippe TOURNÈs, Du phonographe au MP3 : Une histoire de la musique enregistrée - $\mathrm{XIX}^{\mathrm{e}}$-XXI ${ }^{\mathrm{e}}$ siècle, Paris, Autrement, 2008, p. 11-18.

66. TANABE, Meiji ongaku monogatari 明治音楽物語 (Une histoire musicale de l'ère Meiji), Tōkyō, Seiasha 青蛙社, 1965, p. 299-303.

67. Celle-ci succède au mois d'août 1922 à la revue Monde du disque (Chikuonki sekai 蓄音器世界) fondée en 1915 et première revue consacrée au disque au Japon.

68. TANABE, Zoku Tanabe Hisao jijoden 続田辺尚雄自叙层 (Suites de l'autobiographie de Tanabe Hisao), Tōkyō, Hōgakusha, 1981, p. 84-88.

69. Ibid., p. 86.

70. TANABE, Gagaku Tsūkai, op. cit., p. 138-168. Les pochettes des disques et les enregistrements sonores sont tous numérisés et consultables sur le site des Archives numériques des disques de 
78 tours (SPレコードデジタルアーカイブ) du Centre d'études sur la musique traditionnelle japonaise à l'Université municipale des arts de Kyōto (Kyōto shiritsu geijutsu daigaku nihon dentō ongaku kenkyū sentā 京都市立芸術大学日本伝統音楽研究センター), http:// neptune.kcua.ac.jp/cgi-bin/kyogei/index_sp.cgi.

71. Hattatsu no jō kara 発達の上から; TANABE, Gagaku Tsūkai, op. cit., p. 15.

72. TANABE, Gagaku Tsūkai, op. cit., p. 18.

73. Cette dimension du disque a été développée par Mark Katz qui compare l'entraînement à l'écoute et à l'interprétation de la «real music» ou "good music» à l'aide du disque dans l'éducation musicale aux États-Unis au début du xxe siècle, et l'exercice de chanter en chœur au XIX ${ }^{\mathrm{e}}$ siècle ; Mark KATZ, Capturing Sound: How Technology Has Changed Music, Berkekey, University of California Press, 2005, p. 61.

74. 《Tōyō ongaku riron no kagakuteki kenkyūu 東洋音楽理論の科学的研究; Zaidan hōjin keimei-kai daisankai taishō kyūnendo jigyō hōkokusho 財団法人啓明会第三回大正九年度事業報告書 (Rapport annuel de la troisième année d'activité de la fondation d'utilité publique Keimei-kai, $9^{\mathrm{e}}$ année de Taishō [1920]), Tōkyō, Keimei-kai 啓明会, 1921, p. 29-31.

75. UE Sanemichi 上眞行, ōNO Tadamoto 多忠基 et TANABE Hisao, Shōsō-in gakki no chōsa hōkoku 正 倉院楽器の調査報告 (Rapport de recherche sur les instruments de musique du Shōsō-in), Tōkyō, Teishitsu hakubutsukan gakuhō 帝室博物館学報 (Bulletin du Musée impérial), nº 5, 1921.

76. Sur ses études musicales comme «ethnomusicologue», HOSOKAWA Shūhei 細川周平, “In Search of the Sound of Empire: Tanabe Hisao and the Foundation of Japanese ethnomusicology", Japanese Studies, vol. 18, May 1998, pp. 5-19.

77. TANABE, Chōsen riōke no kogakubu : waga kyūchū no bugaku tono kankei 朝鮮李王家の古楽舞 : 我 が宮中の舞楽との関係 (l'Ancienne musique et danse de la cour de la dynastie Ri en Corée: Rapport avec le bugaku de la cour de notre pays), Keimei-kai daigokai kōen-shū 啓明会第五回講演 集, Keimei-kai, septembre 1921, p. 2-6.

78. TANABE, Zoku tanabe hisao jijoden, op. cit., p. 120-121.

79. Voir UEMURA Yukio 植村幸生, «Shokuminchiki chōsen ni okeru kyūtei ongaku no chōsa o megutte : Tanabe Hisao ‘Chōsen gagaku chōsa' no seijiteki bunmyaku» 植民地期朝鮮における宮 廷音楽の調査をめぐって：田辺尚雄『朝鮮雅楽調査』の政治的文脈 (Recherches sur la musique de cour de la Corée durant la colonisation japonaise: le contexte politique des 'Recherches sur le gagaku de Chosǒn' de Tanabe Hisao), Tōkyō, Chōsen shi kenkyūkai ronbun-shū 朝 鮮史研究会論文集, vol. 35, 1997, p. 117-144, ici p.134-138; YАмАмото Hanako 山本華子, Ri ōshoku gagaku bu no kenkyū : shokuminchi jidai chōsen no kyūtei ongaku denshō 李王職雅楽部の研究: 植民地時代朝鮮の宮廷音楽质承 (Recherche sur le département de Gagaku de la dynastie Chosŏn : l'héritage de la tradition de la musique de cour à l'époque de l'occupation japonaise), thèse en musicologie, Université des arts de Tōkyō, 2008, p. 146-169.

80. Journée de protestation pour la restitution de Port-Arthur et de Dairen cédés par la Chine au Japon dans le cadre des « Vingt et une demandes » du Japon en 1915.

81. «Ongaku kara mita tōa kyōei ken»音楽から見た東亜共栄圏 (la Sphère de coprospérité asiatique vue sous l'angle de la musique), Tōyō ongaku no inshō 東洋音楽の印象 (Impressions de la musique orientale), Tōkyō, Jinbun shoin 人文書院, 1941, p. 88-93.

82. Chūgoku chōsen ongaku chōsa kikō 中国 · 朝鮮音楽調査紀行 (Voyage de recherches musicales en Chine et en Corée), Tōkyō, Ongaku no tomo sha, 1970, p. 318-319.

83. 広く東洋音楽の比較研究に基づき、日本音楽史の上に革命的の解釈を与えたものであ る; Id., «Préface », in Nihon ongaku no kenkyū 日本音楽の研究 (Étude sur la musique japonaise), Tōkyō, Kyōbun sha 京文社, 1926.

84. Nihon gakushiin hachijūnen shi 日本学士院八十年史 (Histoire des quatre-vingts ans de l'Académie japonaise), Tōkyō, Nihon gakushiin 日本学士院, 1963, p. 278-280. 
85. KISHIBE Shigeo 岸辺成雄, «Tōyō ongaku gakkai sanjū nen shōshi » 東洋音楽学会三十年小史 (Brève histoire des trente ans de la Société orientale de musique), Tōyō ongaku kenkyū 東洋音楽研 究 (Recherches sur la musique orientale), vol. 19, 1966, p. 63-80.

86. TANABE, «Sōkan ni saishite» 創刊に際して (À l'occasion de la première publication), Tōyō ongaku kenkyū 東洋音楽研究, 1-1, novembre 1937, p. 3.

87. Les chercheurs contemporains de Tanabe tels que Shiratori Kurakichi 白鳥庫吉 (historien de l'Orient, président d'honneur de la Société orientale de musique, 1865-1942) ou Watsuji Tetsurō 和辻哲郎 (philosophe, 1889-1960), ont réagi également au problème de l'orientalisme en préconisant une réappropriation par « l'Oriental». Voir KAN Sang-jung, Orientarizumu no kanata he オリエンタリズムの彼方へ (Au-delà de l'orientalisme), Tōkyō, Iwanami gendai bunko 岩波現代 文庫, Iwanami shoten, 2004, p. 133-162.

88. Erich Moritz von HoRnBostel, Music of the Orient (1928), rééd. Smithsonian Center for Folklife and Cultural Heritage, FW04157, Washington, Folkways Records, 1979.

89. TANABE, Tōa no ongaku 東亜の音楽 (Musique de l'Asie orientale), Columbia-Nipponophone コ ロムビア・ニッポノフォン, Tōkyō, 1941, p. 1-2 de l'appendice.

90. Les pays et les régions (suivant les dénominations en vigueur à l'époque de Tanabe) qui ont fait l'objet d'enregistrements pour ces trois collections sont les suivants : Pour la Musique de l'Asie orientale, la Manchourie, la Chine, la Mongolie, Java, l'île de Bali, la Thaïlande, l'Inde, l'Iran («Perse ancienne» pour Tanabe); pour la Collection de musique de la Grande Asie orientale, la Manchourie, la Mongolie, la Chine, l'Indochine française, la Thaïlande, la Birmanie, la Malaisie, l'Inde, l'Indochine, l'Asie du Sud-Ouest ; pour Musique du sud, la Thaïlande, l'Indochine française, la Malaisie, la Birmanie, Sumatra, l'île de Bali.

91. TANABE, Tōa no ongaku, op. cit., p. 7-8 de l'appendice.

92. Daitōa to ongaku 大東亜と音楽 (la Grande Asie orientale et la musique), publié dans la collection du bureau de l'Enseignement et de l'Éducation (Kyōgaku-kyoku 教学局) sous la dépendance directe du ministère de l'Éducation nationale, en mars 1942. La citation qui suit se trouve p. 21-22.

93. Cela est particulièrement notable dans l'article de Tanabe intitulé « Koten ongaku no bunkazai toshite no kachi »古典音楽の文化財としての価值 (la Valeur de la musique classique comme bien culturel), Bunkazai Geppō 文化財月報, Comité pour la protection des biens culturels, $\mathrm{n}^{\circ} 1$, décembre 1951, p. 6.

94. Bunkazai hogo iinkai 文化財保護委員会, “Gagaku», Liste des biens culturels immatériels, Kikan bunkazai 季刊文化財, vol. 3, 1955, p. 41.

95. Carol GLUCK, "The Past in the Present", in Andrew GORDON (ed.), Postwar Japan As History, Berkeley, Los Angeles, Oxford, University of California Press, 1993, pp. 66-95.

96. Ceux que l'on appelle les «old liberalists»; TSUZUKI Tsutomu 都築勉, Sengo nihon no chishikijin 戦後日本の知識人 (les Intellectuels du Japon d'après-guerre), Yokohama, Seori shobō 世織書房, 1995, p. 123-124 ; OGUMA Eiji 小熊英二, 《Minshu » to 《aikoku»「民主」と「愛国」 (« Démocratie » et « patriotisme »), Tōkyō, Shinyōsha, 2002, p. 175-208.

\section{RÉSUMÉS}

Au début du xxe siècle, Tanabe Hisao (1883-1984), premier musicologue japonais, a élaboré une histoire de la musique japonaise dans laquelle le gagaku était présenté comme une musique 
originale non seulement du Japon, mais aussi de tous les pays asiatiques. Cette notion du gagaku s'accorde avec l'idéologie impériale et coloniale avant-guerre et reste présente jusqu'à nos jours. C'est, par exemple, la décision du ministère japonais de l'Éducation de désigner le gagaku joué par les musiciens de cour du département de Musique de l'Agence impériale comme «bien culturel immatériel important» le 12 mai 1955, qui permet au Japon d'oublier l'histoire de la colonisation musicale au profit d'une relecture plus positive. Le gagaku est alors décrit comme vestige culturel du " continent asiatique ", ce dernier terme se substituant à celui très marqué de «Sphère de coprospérité de la Grande Asie orientale » des années 1940.

At the beginning of the 20th century, Tanabe Hisao (1883-1984), the first Japanese musicologist, elaborated a history of Japanese music in which Gagaku was presented as a original music not only of Japan, but also of all countries in Asia. This concept of Gagaku is consistent with the imperial and colonial ideology before World War II, and still remains up to the present day. It is for example the decision of the Ministry of Education of Japan to designate Gagaku performed by the Court musicians of the Music Department of the Imperial Household as an "Important Intangible Cultural Property" on May 12, 1955, that makes Japan forget the history of musical colonization in aid of more positive re-reading. Gagaku is then described as a cultural relic of the "Asian Continent", a term substituted for that of the "Greater East Asia Co-Prosperity Sphere" in the 1940s.

\section{INDEX}

Index géographique : Corée, Chine

Mots-clés : gagaku, kagura, Tanabe Hisao, musique nationale, colonisation, patrimoine, bien culturel immatériel au Japon, Grande Asie orientale

Thèmes : arts du spectacle

Keywords : Japan, China, Korea, Taishō Period, Meiji Period, Performing Arts, gagaku, kagura, Tanabe Hisao, Colonization, Patrimony, Intangible Cultural Property of Japan, National Music Index chronologique : Meiji (1868-1912), Taishō (1912-1923)

\section{AUTEUR}

\section{SEIKO SUZUKI}

Université Paris Diderot - Paris 7 / Université de Tōkyō 